SALINERO, Sebastián. "Incidencia de la Probabilidad de Condena en los Delitos de Robo. Análisis Descriptivo y Comparado."

Polit. crim. Vol. 4, No 8 (Diciembre 2009), Art. 5, pp. 430-474 (1-45).

[http://www.politicacriminal.cl/Vol_04/n_08/Vol4N8A5.pdf]

\title{
Incidencia de la Probabilidad de Condena en los Delitos de Robo. Análisis Descriptivo y Comparado.*
}

\author{
Sebastián Salinero Echeverría \\ Magíster (C) en Derecho Penal de la Universidad de Talca \\ ssalinero@utalca.cl
}

\section{Resumen}

Este artículo se inspira en la metodología utilizada en el estudio "Factores Determinantes de la Criminalidad en Chile" desarrollado por el Centro de Estudios de Derecho Penal de la Universidad de Talca. Se expone en un primer término la evolución dentro de un período de tiempo de las estadísticas de Chile, Estados Unidos y España relativas a las denuncias criminales, condenas, suspensión de las penas y población penal. En un segundo término, se analiza bajo criterios estadísticos de correlación, las relaciones existentes entre la comisión de los delitos de robo con fuerza y robo con violencia y las siguientes variables: población penal, suspensión de la pena y condenas. En tercer lugar, se exponen los índices de probabilidad de condena de los delitos de robo. Se concluye en la investigación, entre otras, que el aumento de la probabilidad de condena implica una disminución real en la comisión de los delitos de robo.

\section{Palabras clave}

Probabilidad de Condena, Encarcelar, Suspensión de la Pena, Robo.

\begin{abstract}
This article is based on the methodology used in the study "Determinants of Crime in Chile", developed by the Centre for the Study of Criminal Law at the University of Talca. Firstly, it explains the evolution of Chilean, American, and Spanish statistics on criminal activity reporting, sentencing, probation, and the number of prisoners, over a certain period of time, and offers a comparative analysis of the results. Secondly, using statistical correlation criteria, it analyzes the relationship between burglary, and the number of prisoners, probationers and convictions. Thirdly, it shows the probability of conviction rates for burglaries and theft. Finally, the research concludes that an increase in the probability of being convicted results in a real reduction in committed burglaries.

\footnotetext{
* Tesis expuesta para la obtención del grado académico de Magíster en Derecho Penal de la Universidad de Talca, dirigida por el Dr. Iñigo Ortiz de Urbina y Dr. Jean Pierre Matus Acuña, a quienes agradezco su dedicación, orientación y sabios consejos. Este trabajo también recoge las valiosas aportaciones de la comisión examinadora y del Profesor Matus.
} 
SALINERO, Sebastián. "Incidencia de la Probabilidad de Condena en los Delitos de Robo. Análisis Descriptivo y Comparado."

\section{Key words}

Probability of conviction, Imprisonment, Probation, Burglary.

\section{Introducción}

En Chile, la tasa de denuncias de los denominados delitos de mayor connotación social, que en adelante denominaremos con la sigla DMCS -aquellos calificados como tales por la División de Seguridad Pública del Ministerio del Interior de Chile con el objeto de medir la delincuencia en base a diferentes factores- ${ }^{1}$ presentan en los últimos diez años un crecimiento en torno al $115 \%{ }^{2}$

Este crecimiento de la tasa de denuncias nos hace reflexionar sobre el problema de la delincuencia, el cual, para muchos chilenos, no es una cuestión secundaria, ${ }^{3}$ sino más bien, prioritaria, que requiere atención por parte de los diversos sectores de la sociedad. Desde esta perspectiva en este estudio criminológico me he propuesto como objetivo, por una parte, presentar el problema de la delincuencia, mediante la descripción estadística ${ }^{4}$ del comportamiento de diferentes tópicos, como la denuncia, condenas, suspensión de la pena y población penal en Estados Unidos, España y Chile, para luego proceder a relacionarlos a través del método estadístico bivariado de Pearson, como fuese utilizado con éxito en el estudio "Factores Determinantes de la Criminalidad en Chile". ${ }^{5}$ El muestreo de tres países con características jurídicas disímiles entre sí permitirá realizar un análisis comparativo ${ }^{6}$ que nos ayudará a observar las similitudes y diferencias entre las diversas culturas expuestas y así de esta manera, experimentar y extraer diversas conclusiones. Consecuentemente, con los datos obtenidos en el objetivo anteriormente dicho, construiré los índices de probabilidad de condena de los países ya mencionados, con el fin de mostrar la plausibilidad empírica de que para la disminución de la comisión de delitos debe

\footnotetext{
${ }^{1}$ Se consideran DMCS los delitos de robo con fuerza, robo con violencia, robo con intimidación, robo por sorpresa, hurto, lesiones, homicidio y violación.

${ }^{2}$ Infra subapartado 2.1.1.

3 Para el Centro de Estudios Públicos, en la Encuesta Nacional de Opinión Pública, de junio 2008, la "delincuencia" es para la ciudadanía el problema mayor que el gobierno debe solucionar. Véase también al respecto el diario El Mercurio de 28 de diciembre del año 2007: la delincuencia, la salud y la pobreza constituyen los problemas centrales que la ciudadanía señala que deben ser atendidos prioritariamente por las autoridades.

${ }^{4}$ Una crítica al uso de la estadística descriptiva en Criminología puede verse en: GONZALEZ BERENDIQUE, Marco, Criminología, tomo I, Santiago: Ed. Jurídica, 2004, p. 91: "Estas Estadísticas descriptivas, no obstante, distan mucho de permitir un conocimiento: a) de la real magnitud del delito; b) de los mecanismos que han conducido a la criminalidad." (La cursiva es de su autor).

5 RUIZ, Paulina; CEA, Macarena; RODRÍGUEZ, Carlos; MATUS, Jean Pierre, "Determinantes de la criminalidad: Análisis de Resultados". Polit. crim. n 3 (2007), pp. 1-80. Una versión digitalizada puede verse en http://www.politicacriminal.cl/n_03/d_1_3.pdf [visitada el 15.08.2008]. También se utiliza el método estadístico bivariado de pearson, aunque no se reconoce expresamente en la metodología empleada en: ARAYA MOYA, Jorge; SIERRA CISTERNAS, David, "Influencia de factores de riesgo social en el origen de conductas delincuenciales. Índice de vulnerabilidad social-delictual". Serie de estudios, División de Seguridad Pública, Ministerio del Interior, Gobierno de Chile, Junio (2002), pp. 3-82, p. 31.

${ }^{6}$ Mediante un análisis comparativo estudiamos especies que pertenecen al mismo grupo pero que difieren en algunos aspectos. Estas diferencias llegan a ser el foco de la examinación. La meta es descubrir por qué los casos son diferentes: revelar la estructura subyacente general que genera o permite tal variación.
} 
Polit. crim. Vol. 4, No 8 (Diciembre 2009), Art. 5, pp. 430-474 (1-45).

[http://www.politicacriminal.cl/Vol_04/n_08/Vol4N8A5.pdf]

aumentar la probabilidad de condena, de esta manera, tratare de compatibilizar en Chile, parte del modelo propuesto por el Nóbel Gary Becker. ${ }^{7}$

El estudio considera todo el territorio nacional, así como la integridad de los países comparados ya mencionados. El periodo de análisis se ocupa de los años 1998 a 2007, en el caso chileno y, en el caso comparado, tomando los datos más recientes que se reporten en sus fuentes. ${ }^{8}$

Para lograr los cometidos de la investigación, el estudio contendrá cinco capítulos, además de esta introducción. El primer capítulo contendrá los objetivos del trabajo y la explicación de la metodología que se utilizó para la realización del mismo, exponiéndose el procedimiento aplicado para lograr las correlaciones entre las variables analizadas; el segundo capítulo estará compuesto por la descripción de los datos obtenidos en la investigación para los diversos países manifestados y un somero análisis de los mismos; el capítulo tercero está referido al procedimiento de correlación de variables; el cuarto capítulo se refiere a la exposición de probabilidades, y el quinto y último capítulo, describirá las conclusiones alcanzadas.

\section{Objetivos y Metodología.}

Advirtiendo la insuficiencia de la información, especialmente en Chile, uno de los objetivos es describir en un determinado período de tiempo, las estadísticas ${ }^{9}$ de las denuncias de los DMCS, ${ }^{10}$ las condenas de los DMCS, la suspensión de la pena y la población penal general en España, Estados Unidos y Chile. Estas variables las cuantificare en la unidad de medida denominada "Tasa", ${ }^{11}$ que permitirá realizar las comparaciones entre los diversos países expositores. Para analizar cada país construiré una base de datos, que es alimentada con la

\footnotetext{
${ }^{7}$ Véase BECKER, Gary, "Crime and Punishment: An Economic Approach", Journal of Political Economy 76 n² (1968), pp. 169-217. También se puede ver una crítica al modelo de Becker: En ARAYA/SIERRA. Influencia, cit. nota $\mathrm{n}^{\mathrm{o}} 5$, p.10: "Este tipo de modelos explicativos resumen una conducta racional guiada por la conveniencia, obviando las circunstancias sociales que rodean a estos sujetos. Esta línea no da razón del por qué sólo algunos sujetos en una sociedad asumen este raciocinio u otros, conscientes de una ecuación que reporta probables beneficios, no desarrollan este comportamiento." (la cursiva es mía).

${ }^{8}$ El estudio se basa en unidades de tiempo de larga frecuencia (anuales), ya que esta es la información de que se dispone para el caso chileno.

${ }^{9}$ Las Estadísticas, como método de la Criminología como ciencia empírica es criticada por algunos. Véase: HERRERO HERRERO, Cesar, Criminología. Parte General y Especial, Madrid: Dykinson, 2007, p. 267: "En cuanto a los inconvenientes, uno de ellos dice relación con la utilización por parte de las distintas estadísticas oficiales, de terminología materialmente idéntica y significativamente distinta." También se critica, hacer estadísticas de un periodo de tiempo demasiado largo porque se corre el peligro de que los datos sobre la evolución de la delincuencia se deba a esquemas formales externos: como por ejemplo cambios de la legislación penal, cambios procesales, e incluso, de pura técnica estadística de recolección de datos.

${ }^{10}$ Se utiliza las denuncias y no los delitos efectivamente cometidos porque no existen datos acerca de estos últimos. Es evidente que no todos los delitos son denunciados. A manera de ejemplo, según información entregada por el Ministerio del Interior, en Noviembre de 2005, un 44,2\% de los robos con y sin violencia eran denunciados.

${ }^{11}$ Cada 100.000 habitantes corresponde al estándar internacional que se usa para presentar las estadísticas de delitos con el fin de corregir las cifras por el efecto de la población. "La Tasa" es una frecuencia relativa con que se producen ciertos acontecimientos, en relación a la población media existente durante el tiempo en que se han registrado tales acontecimientos.
} 
SALINERO, Sebastián. "Incidencia de la Probabilidad de Condena en los Delitos de Robo. Análisis Descriptivo y Comparado."

información obtenida desde organismos oficiales pertenecientes a cada exponente, quienes la publican en Internet. Además, recurriré a diversos autores con el objeto de extraer otros datos importantes que aporten la mayor cantidad de información al estudio en cuestión. Disponiendo de estas fuentes, estimo que obtendré información relativamente confiable y de validez para alcanzar los objetivos propuestos. ${ }^{12}$ Luego, analizaré los datos estadísticos recolectados, estudiaré cuál es la relación entre la denuncia del delito de robo, versus, población penal; denuncia de delito de robo, versus, suspensión de la pena y, denuncia de delito de robo, versus, condenas. ${ }^{13}$ Para el procedimiento de correlación, en la variable denuncia, se optó por tener como indicador no a los DMCS, sino únicamente al robo con fuerza. ${ }^{14} \mathrm{Al}$ igual que el modelo seguido, se ha seleccionado la tasa de denuncia de robo con fuerza para medir la delincuencia, ${ }^{15}$ pues se ha considerado que presenta menos

${ }^{12}$ Para el caso de Chile, hemos utilizado los datos disponibles en fuentes públicas, tales como, el Instituto Nacional de Estadísticas, Ministerio Público, División Seguridad Pública del Ministerio del Interior y Gendarmería de Chile. Es necesario destacar que algunas de estas fuentes, en sus procesos de recolección de datos, no cuentan con la prolijidad requerida; y otros organismos cuentan con información insuficiente que impide la realización de regresiones como las ejecutadas en los países comparados. Para España, se utiliza la información obtenida desde el Ministerio del Interior, Policía de España e Instituto Nacional de Estadística de ese país. En el caso de los Estados Unidos, se recurrió al FBI y Departamento de Justicia. Hemos utilizado y trabajado únicamente sobre los datos publicados en sus sitios de Internet, corroborándolos, en la medida de lo posible, con otras entidades públicas y privadas, y otras investigaciones afines. De este modo, los resultados que aquí se exponen pueden considerarse hipótesis de trabajo para una investigación más amplia.

${ }^{13}$ Esta metodología de estudio es bastante criticada cuando se basa sobre datos agregados, referidos no a individuos sino a grupos secundarios y mediciones que no han sido realizadas directamente por los investigadores, sino tomadas desde agencias oficiales. Una crítica, sobre todo respecto de la utilización de datos agregados para establecer los efectos preventivos de las penas, puede verse en: SERRANO MAILLO, Alfonso, Introducción a la Criminología, Lima-Perú: Edit. Ara, 2004, p. 266.

${ }^{14}$ A manera de ejemplo, conforme a las estadísticas anuales de la División Seguridad Pública del Ministerio del Interior de Chile, correspondiente al año 2007, el delito de robo con fuerza, fue el ilícito más cometido en dicho período con una tasa de denuncia ascendente a 1018,9 (Por cada 100.000.- habitantes).

${ }^{15}$ RUIZ/CEA/RODRÍGUEZ/ MATUS, "Determinantes", cit. nota $n{ }^{\circ} 5$, p. 6 y ss, quienes señalan: "La tasa de denuncia de robo con fuerza, para medir la delincuencia, es el delito que menos problemas tiene. Además, para Chile tiene mucha importancia, por ser el ilícito que tiene mayor peso porcentual dentro de los delitos considerados como los más relevantes, es decir, los delitos de mayor connotación social." Como bien indican los autores, "las características con las que cuenta el robo con fuerza para ser seleccionado como el relativamente mejor son las siguientes: en primer lugar, su conceptualización en el Código Penal ha sido mantenida en el tiempo, esto es, que se ha entendido por muchos años de la misma forma y no se ha introducido ningún tipo de cambio en sus especificaciones. En segundo lugar, la conceptualización de este delito es ampliamente entendida por la mayoría de las personas. Se entiende que existe Robo con fuerza cuando se ejerce fuerza sobre un bien ajeno para ser robado ya sea, ese mismo bien o, algo de su interior (por ejemplo el robo a casas, a autos, de autos. El que su definición sea práctica, simple y clara hace que no haya espacio para dudas y que, por lo tanto, las personas que cometen este delito lo efectúan perfectamente, toda vez, que la mayoría lo entiende de la misma manera. Esto nos lleva a deducir que las denuncias de este delito son más confiables a lo largo del tiempo. En tercer lugar, los costos que producen a las víctimas este tipo de delitos son costos materiales cuantificables (sin considerar los costos psico-emocionales que puedan tener las personas víctimas de delitos), que hacen que se generen expectativas de que pueden recuperar lo perdido. Por esta razón, las personas tenderían a denunciar más este tipo de delito, es decir, existe mayor disposición o interés en denunciar ya que esperan recuperar lo que les ha sido robado. En este sentido, se puede afirmar que la relación o razón entre la capacidad de denunciar en las personas víctimas de este tipo de delito y la efectiva denuncia de éste es más cercana a uno, esto porque existen incentivos reales de recobrar lo perdido y porque no existen desincentivos a denunciar, propios de otros delitos, por no incluir éstos elementos que toquen la dignidad, ni la intimidad de las personas (como los delitos sexuales o las violencia intrafamiliar), ni esperarse represalias al denunciarlo, como si se podrían esperar al denunciar delitos violentos (lesiones, robo con 
Polit. crim. Vol. 4, No 8 (Diciembre 2009), Art. 5, pp. 430-474 (1-45).

[http://www.politicacriminal.cl/Vol_04/n_08/Vol4N8A5.pdf]

inconvenientes en relación a la llamada cifra negra, que no es sino, la falta de denuncia efectiva atribuida a diversos factores. ${ }^{16} \mathrm{~A}$ su vez, incluiré el robo con violencia dado que, la experiencia en este tipo de estudios y conforme al modelo seguido, explica que es necesario incluir una variable de control que permita observar como se mueven las variables independientes que he escogido, pero relacionándola con otra variable dependiente. ${ }^{17}$

Aclaro que mí objetivo es mostrar relaciones, y no causalidad, entre una y otra variable. También, hago presente que las relaciones existentes entre las diversas variables no son las únicas determinantes que podrían incidir en su comportamiento, pudiendo existir otras que no son materia de este estudio. ${ }^{18}$

Esta comparación, dado las diferencias que tienen estos delitos, nos podrá decir si las variables independientes tienen relaciones similares o diversas para cada delito, lo que nos podría dar una pauta probable de interpretación acerca de si estos elementos (variables independientes) se están relacionando con la delincuencia en general o con cada delito en particular.

Se utiliza la denuncia como proxy de la criminalidad $^{19}$ y no los datos obtenidos desde la Encuesta Nacional Urbana de Seguridad Ciudadana (ENUSC), ${ }^{20}$ en razón de que ésta

violencia)." El paréntesis es de los autores. Por su parte, tratándose de España, el delito de robo con fuerza previsto en los artículos 237 y siguientes del Código Penal Español, es similar al regulado en nuestra legislación penal, de manera que, no se presenta ningún inconveniente para su comparación. Para el caso de Estados Unidos, utilizamos el denominado "Burglary". Este delito es definido en el Informe Uniforme de Delito (UCR) emanado del FBI como: el robo con allanamiento de morada o en una estructura. El Programa tiene tres subclasificaciones de robo: con fuerza para la entrada, entrada ilegal sin fuerza, y la tentativa de entrada forzada. La UCR en la definición de "estructura" incluye, por ejemplo, apartamento, establo, casa remolque o casa flotante cuando se utiliza como vivienda permanente, oficina, carro de ferrocarril (pero no del automóvil), establo, y el buque (es decir, barcos).

${ }^{16}$ Cfr. FUKUYAMA, Francis, La Gran Ruptura, La Naturaleza Humana y la Reconstrucción del Orden Social, Trad. PLACKING DE SALCEDO, Dorotea, Buenos Aires: Edit. Atlántida, 1999, p.59. Según una estimación, los robos denunciados constituyen solo del 44 al 63 por ciento de los realmente cometidos. Conforme la Encuesta Nacional Urbana de Seguridad Ciudadana 2007(ENUSC), sólo el 35,7\% de los delitos fueron denunciados en ese período. http://www.seguridadciudadana.gob.cl/filesapp/Boletin_ENUSC 2007.pdf [visitada el 22.03.2009]. Para el informe de la Internacional Crime Victims Survey 2004 (ICVS) sólo se denuncia 1 de cada 4 delitos (25\%). En: http://rechten.uvt.nl/icvs/pdffiles/ICVS2004_05.pdf [visitada el 23.03.2009].

${ }^{17}$ Para los efectos de este estudio se entiende por robo con violencia tanto el robo con intimidación y el robo con violencia propiamente tal.

${ }^{18}$ Conforme al Diccionario de la Real Academia de la Lengua Española, debemos entender por causa: aquello que se considera como fundamento u origen de algo, y por relación: la conexión, correspondencia de algo con otra cosa.

${ }_{19}$ Además de lo que se señala, es criticado el hecho de la utilización de la denuncia como proxy de la delincuencia en razón de no ser una variable exógena, sino más bien endógena, lo que impediría la existencia de imparcialidad o produciría cierto sesgo en la medición de la delincuencia. La denuncia puede estar condicionada por múltiples factores, como por ejemplo: En el caso hipotético que aumente las pólizas de seguros, es probable que aumenten las denuncias como requisito para cobrar una indemnización. También puede estar condicionada por las facilidades que exista para denunciar, por ejemplo la utilización del teléfono o Internet. Véase: GARRIDO, Vicente; STANGELAND, Per; REDONDO, Santiago, Principios de Criminología, $3^{\circ}$ Ed., Valencia: Tirant Lo Blanch, 2006. En mismo sentido: STANGELAND, Per, "Encuestas 
SALINERO, Sebastián. "Incidencia de la Probabilidad de Condena en los Delitos de Robo. Análisis Descriptivo y Comparado."

empezó a aplicarse el año 2003, lo que me impediría realizar el análisis de una serie mayor de tiempos que se requiere para la presente exposición. También hago presente que la encuesta pudiese parecer más idónea, ya que sus datos no proceden de las agencias del sistema legal sino de la propia víctima del delito. Además, la encuesta excluye la denominada "cifra negra", ${ }^{21}$ permite comprobar si la víctima denuncia o no el delito a las autoridades encargadas de la persecución y si ésta es efectiva. ${ }^{22}$

Las variables independientes, población penal, suspensión de la imposición de la pena y condenas, serán testeadas principalmente con correlaciones. Se harán correlaciones bivariadas de Pearson. ${ }^{23}$ Se considerarán como relaciones significativas desde un 90\%, teniendo en cuenta que lo más seguro y común en el análisis estadístico es el $95 \%$ de confianza. ${ }^{24}$ También graduare el resultado de correlación, sea este positivo o negativo, en "Bajo" cuando el índice obtenido sea menor a 50\%, en "Medio" cuando no supere el 70\% y en "Alto" cuando esté por sobre dicho índice.

Seguidamente, mí objetivo será construir, con los datos obtenidos-tasa de denuncia y tasa de condenas - las tablas de índices de probabilidad de condena en los delitos de robo con fuerza y robo con violencia para Estados Unidos, España y Chile.

Los resultados obtenidos permitirán verificar empíricamente las hipótesis de este trabajo, a saber: i) si la población penal incide en el aumento o disminución de la tasa de denuncia de los delitos de robo; ii) si el comportamiento de la suspensión de la pena produce algún efecto, positivo o negativo, en la dinámica de la denuncias de los delitos aludidos; y iii) si se cumple en Chile la tesis de la disuasión de Becker, esto es, si el aumento de la probabilidad de condena produce algún efecto inverso en estos delitos.

de Victimización" en: DIEZ RIPOLLES, José Luis; CEREZO DOMINGUEZ, Ana Isabel, Los Problemas de la Investigación Empírica en Criminología: La situación española, Valencia: Tirant Lo Blanch, 2001, p. 12.

${ }^{20}$ La Encuesta Nacional Urbana de Seguridad Ciudadana (ENUSC) es elaborada anualmente por el Ministerio del Interior de Chile. Se lleva a cabo mediante cuestionarios estructurados en los que se pregunta al encuestado, entre otras cosas, si ha sido víctima o no de algún delito (con independencia de que este haya sido denunciado o no a la policía).

${ }^{21}$ La cifra negra alude a un cociente (concepto aritmético) que expresa la relación entre el número de delitos efectivamente cometidos y el de delitos estadísticamente reflejados. GARCIA-PABLOS DE MOLINA, Antonio, Tratado de Criminología, $3^{\circ}$ Ed., Valencia: Tirant Lo Blanch, 2003, p. 264.

${ }^{22}$ Cfr. GARCIA-PABlOS, Tratado de Criminología, cit. nota $\mathrm{n}^{\circ} 21$, p. 274 . Se trata de uno de los instrumentos más útiles para llevar a cabo una comparación de las tasas de criminalidad oficiales y no oficiales, detectando las cifras negras de las infracciones de escasa trascendencia.

${ }^{23}$ Es un índice estadístico que mide la relación lineal entre dos variables cuantitativas.

${ }^{24}$ RUIZ/CEA/RODRÍGUEZ/ MATUS, "Determinantes" cit. nota $\mathrm{n}{ }^{\circ} 5$, p. 4, proponen el $90 \%$ como nivel de confianza. 
Polit. crim. Vol. 4, № 8 (Diciembre 2009), Art. 5, pp. 430-474 (1-45).

[http://www.politicacriminal.cl/Vol_04/n_08/Vol4N8A5.pdf]

\section{Descripción de la Denuncias, Condenas, Suspensión de la Pena y Población Penal en Chile y países comparados.}

Para un mayor orden del estudio expondré los resultados estadísticos por tópicos y países.

\subsection{Las Denuncias.}

Conforme al Diccionario de la Real Academia de Lengua Española, la denuncia la debemos entender como dar a la autoridad judicial o administrativa parte o noticia de una actuación ilícita o de un suceso irregular.

Las limitaciones que presenta la utilización de la denuncia como fuente de conocimiento de la cuestión criminal pueden reunirse bajo dos rubros: la cuestión de la "cifra negra de la criminalidad" y la del "carácter manufacturado" de las estadísticas oficiales.

La "cifra negra de la criminalidad" representa el conjunto de conductas realizadas efectivamente en la vida social que presuntamente se asocian a las tipificaciones contenidas en la ley penal, que no han sido registradas y oficializadas por las agencias estatales competentes, instituciones policiales y judiciales. Muchas variables inciden en esta distancia entre "criminalidad real" y "criminalidad aparente" en el caso de las estadísticas oficiales: a) la falta de motivación de los ciudadanos para denunciar el hecho presuntamente delictuoso a las policías - porque se considera que el daño ocasionado es demasiado leve como para justificar el costo de llevar adelante ese tramite administrativo, pues se considera que las policías son inefectivas u hostiles, o porque la víctima puede tener algún grado de involucramiento en el hecho presuntamente delictuoso, o porque la víctima puede ser vulnerable socialmente frente a potenciales represalias, etc.-; b) la institución policial frente a la denuncia de un ciudadano, en ciertos casos, desestima que se trate de un hecho presuntamente delictuoso, puede directamente no actuar para comprobar si es o no un hecho presuntamente delictuoso pues no posee capacidad institucional o los miembros que reciben la denuncia no desean hacerlo; c) el ministerio público puede desechar la denuncia realizada como infundada, etc. Es decir, existe una larga cadena de interpretaciones, decisiones y acciones entre la realización efectiva de un hecho presuntamente delictivo y su registro y oficialización por las instituciones policiales y judiciales.

Por otro lado, las criminologías sociológicas han venido problematizando el "carácter manufacturado" de las estadísticas oficiales sobre la criminalidad. Es decir, que las estadísticas policiales y judiciales dependen fundamentalmente de las decisiones de registro $\mathrm{y}$ oficialización de hechos presuntamente delictuosos tomadas por miembros de la institución policial y judicial, en función de parámetros culturales que no son homogéneos a través del tiempo y el espacio y sobre las cuales inciden múltiples variables de diversa naturaleza. 
SALINERO, Sebastián. "Incidencia de la Probabilidad de Condena en los Delitos de Robo. Análisis Descriptivo y Comparado."

\subsubsection{La Situación en Chile.}

Los informes estadísticos elaborados por la División de Seguridad Pública del Ministerio del Interior sobre la base de denuncias presentadas a Carabineros y Policía de Investigaciones de Chile, dan cuenta que desde finales de la década de los noventa hasta la actualidad, la tasa de denuncia de los DMCS ha ido en constante aumento. ${ }^{25}$

Cabe hacer presente que para la gran mayoría, entre los cuales me cuento, la medición de la delincuencia vía denuncia de delitos, que usa tanto el Ministerio del Interior como el Ministerio Público -aunque este último en una versión más completa- presenta una serie de deficiencias metodológicas, ${ }^{26}$ que hacen a las encuestas de victimización un sistema más confiable. ${ }^{27}$

Hecha esta advertencia, entrare a analizar la Tabla 1, la que muestra que entre los años 1998-2007, la tasa de denuncias por cada 100.000 habitantes aumentó en un 115\%, mientras que el total de denuncias presentadas en igual período anotó un crecimiento total de un $138 \%{ }^{28}$

Tabla 1. Evolución en Chile del Total de Denuncias y Tasa Total por cada 100.000 habitantes de Delitos de Mayor Connotación Social entre los años 1998-2007. ${ }^{29}$

\begin{tabular}{c|ccc}
\hline \multicolumn{4}{|c}{ Chile } \\
\hline Año & Denuncias & Tasa & Variación Tasa \\
\hline 1998 & 243.449 & $1.623,4$ & \\
1999 & 291.464 & $1.917,9$ & $+18,1$ \\
2000 & 315.760 & $2.050,7$ & $+6,9$
\end{tabular}

${ }^{25}$ La tasa no se construye con los datos obtenidos a partir de la Encuesta Nacional Urbana de Seguridad Ciudadana (ENUSC), elaborada por el Ministerio del Interior, en razón a que ésta empezó a aplicarse el año 2003, lo cual nos impediría realizar el análisis de una serie temporal que se requiere para el presente estudio.

${ }^{26}$ Según el Instituto Libertad y Desarrollo, las estadísticas de denuncias del Ministerio del Interior considera 8 categorías de delitos (DMCS). Las del Ministerio Público consideran 17 categorías. El problema de ambas, más de la primera que la segunda, es que subrepresenta el universo de delitos. Además, las denuncias de delitos presentan una complejidad adicional: dado que diversas encuestas de victimización han mostrado en forma consistente, en la última década, que los índices de denuncia no superan el 50\% para la mayoría de los delitos. Los aumentos en las denuncias pueden ser causados, tanto por una disminución en la "cifra negra" (la brecha entre delitos efectivamente ocurridos (100\%) y aquellos que se denuncian (50\%)) o simplemente que aumentan los delitos.

${ }^{27}$ Una crítica al modelo de encuesta puede verse en: GARRIDO/STANGELAND/REDONDO, Principios, cit. nota $\mathrm{n}^{\circ} 19$, p. 97: "la entrevista personal es un método tradicional y eficaz para obtener información, pero a la vez costoso y proclive a variaciones según como actúe el entrevistador." También en STANGELAND, Encuestas de Victimización, cit. nota $\mathrm{n}^{\mathrm{o}} 19, \mathrm{p} .15$.

${ }^{28} \mathrm{Al}$ contrario de la denuncia, la Encuesta Nacional Urbana de Seguridad Ciudadana (ENUSC) muestra un descenso en la victimización general. El año 2003 la victimización era en orden al 43,0\%, en circunstancias que el año 2007 es de 34,8\%. En: http://www.seguridadciudadna.gob.cl [visitado el 10.12.2008].

${ }^{29}$ En el ítem denuncias y tasa se incluyen las denuncias propiamente tales y las detenciones. Nótese que se puede dar la paradoja de que exista una doble lectura para un sólo delito, en el evento que se registre en una primera oportunidad la denuncia del hecho y luego la detención del autor de ese mismo hecho. Con esta posibilidad de doble cuenta puede ocurrir que la eficiencia de la policía a la hora de conseguir más detenciones suponga un incremento de la tasa. 
Polit. crim. Vol. 4, No 8 (Diciembre 2009), Art. 5, pp. 430-474 (1-45).

[http://www.politicacriminal.cl/Vol_04/n_08/Vol4N8A5.pdf]

\begin{tabular}{l|lll}
2001 & 374.477 & $2.404,9$ & $+17,2$ \\
2002 & 422.056 & $2.680,5$ & $+11,4$ \\
2003 & 503.202 & $3.160,9$ & $+17,9$ \\
2004 & 524.707 & $3.260,5$ & $+3,1$ \\
2005 & 525.522 & $3.230,5$ & $-0,9$ \\
2006 & 529.968 & $3.225,1$ & $-0,1$ \\
2007 & 580.236 & $3.495,8$ & $+8,3$ \\
\hline
\end{tabular}

Fuente: Elaboración propia a partir de los datos del Ministerio del Interior: http://www.seguridadciudadana.gov.cl/

Por su parte, en el Ministerio Público se ingresaron en el año 2007 la cantidad de 1.078.307 denuncias, existiendo respecto del año 2005 un aumento ascendente al $42 \%{ }^{30}$ Esta variación positiva se podría explicar por la entrada en vigencia paulatina, en las distintas regiones del país, de la reforma procesal penal.

Según la Fundación Paz Ciudadana, ${ }^{31}$ estas cifras pudiesen parecer preocupantes, no sólo por la magnitud, sino también por el aumento que experimentó en la presente década el gasto en Orden y Seguridad Pública, que creció en $121 \%$, es decir, pasó de los $\$ 30.000$ per capita, que era en el año 1996, a los \$ 60.000 el 2006. ${ }^{32}$ Se podría pensar que esta mayor cantidad de recursos destinados para seguridad pública, no logran una disminución en las tasa de denuncia de los DMCS, entre otras posibles causas, por la falta de eficiencia en la utilización de esos fondos o recursos. ${ }^{33}$

\footnotetext{
${ }^{30}$ Véase al respecto el Boletín Estadístico Ministerio Público año 2007, en http://www.ministeriopublico.cl [visitado el 20.07.2008].

${ }^{31}$ El 2 de abril de 1992 se crea la Fundación Paz Ciudadana, institución de derecho privado, sin fines de lucro y no partidista, que tiene como objetivo contribuir a la disminución de la delincuencia a través de la colaboración técnica para la formulación de políticas y del desarrollo y transferencia de herramientas de trabajo. Desde entonces, la institución cuenta con la colaboración de representantes del sector empresarial, de los medios de comunicación y del mundo político y académico del país. En http://www.pazciudadana.cl [visitado 19.11.2008]

${ }^{32}$ El aumento en el gasto en Orden y Seguridad Pública esta sólo referido al gasto en seguridad pública. Véase Balance Delincuencia año $2006 \mathrm{Paz}$ Ciudadana, en http://www.pazciudadana.cl [visitado el 22.07.2008].Según El Mercurio de 12 de Octubre del 2008, el presupuesto anual en Seguridad Privada es de US\$ 900 millones, frente a los US\$ 800 millones de Carabineros de Chile. A su vez, en esta misma edición, se establece que el contingente de guardias del sector privado es de 98.500 efectivos, frente a los 40.000 que conforman la plana de Carabinero de Chile.

${ }^{33}$ Un estudio económico realizado en Colombia estableció que los delitos de homicidio y secuestro presentaban un constante aumento, pese a existir paralelamente un crecimiento sostenido en el gasto de defensa, justicia y seguridad. Se atribuyó como causa la falta de eficiencia en la utilización de los recursos. POSADA, Carlos; GONZALEZ, Francisco, "El gasto en defensa, justicia y seguridad". Rev. econ. Inst., vol. 2, $\quad \mathrm{n}^{\mathrm{0}} \quad 2, \quad$ Jan/June $\quad(2000), \quad \mathrm{pp} . \quad 53-75, \quad$ en: http://www.scielo.org.co/scielo.php?script=sci arttext\&pid=S012459962000000100004\&lng=en\&nrm=iso $>$.

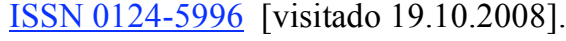


SALINERO, Sebastián. "Incidencia de la Probabilidad de Condena en los Delitos de Robo. Análisis Descriptivo y Comparado."

\subsubsection{La Situación en Estados Unidos.}

Como se advierte en la Tabla 2, elaborada según el $\mathrm{UCR}^{34}$ (Uniform Crime Reports), en los Estados Unidos, en el período 1998 - 2006, la tasa de denuncia reporta una caída de $17,5 \%{ }^{35}$

En el caso estadounidense, para explicar la baja criminalidad, el profesor Steven Levitt nos señala que la mayoría de las supuestas explicaciones ofrecidas, entre ellas, la solidez de la economía, los cambios demográficos, las mejores estrategias policiales, las leyes de control sobre porte legal de armas y un aumento en la aplicación de la pena de muerte, no juegan un rol directo en el descenso de la criminalidad. Por el contrario, existen cuatro factores que determinan prácticamente todo el descenso visto en la criminalidad: el incremento del número de policías, el aumento de la población penal, la disminución de la epidemia de crack y la legalización del aborto. ${ }^{36}$

En el ámbito de eventuales modificaciones que hubiese tenido Estados Unidos en el ámbito penal, es necesario mencionar la Omnibus Crime Bill de 1994 que buscaba, entre otras cosas, construir más prisiones, poner en las calles cien mil nuevos policías, permitir la pena de muerte para más delitos federales y prohibir 19 armas semiautomáticas.

Tabla 2. Evolución en Estados Unidos de la Tasa de Denuncias por cada 100.000 hab. de los denominados Delitos de Mayor Connotación Social entre 1998-2006.

\begin{tabular}{l|lc}
\hline \multicolumn{3}{|c}{ Estados Unidos } \\
\hline Año & Tasa & Variación \\
\hline 1998 & 4.620 & $-6,2$ \\
1999 & 4.267 & $-7,6$ \\
2000 & 4.125 & $-3,3$ \\
2001 & 4.163 & $+0,9$ \\
2002 & 4.125 & $-0,9$ \\
2003 & 4.063 & $-1,5$
\end{tabular}

\footnotetext{
${ }^{34}$ El programa Uniform Crime Report (Informe Uniforme de Delito) es administrado por el FBI, quién tiene la tarea de recolectar, publicar y archivar datos estadísticos confiables sobre los delitos. Los delitos comprendidos en el UCR se dividen en violentos (homicidios, violación, robo violento, agresiones graves) y contra la propiedad (robo con fuerza en lugar habitado, hurtos, robo de vehículos). Fuente: http://www.fbi.gov/UCR. Pese a las bondades estadísticas del UCR, la Comisión del presidente Johnson estimó que la violación era tres veces más frecuente que la denunciada y que la cifra del robo con violencia debía aumentarse en un 50\%: Véase. The Challenge of Crime in a Free Society, A report by the President's Commission on Law Enforcement and Administration of Justice, U.S. Government Printing Office, Washington, February 1967. En: GONZALEZ, Criminologia, cit. nota ${ }^{\circ}$ 4, p. 73.

${ }^{35} \mathrm{Al}$ contrario de la denuncia, la Encuesta de Victimización (NCVS) muestra un ascenso en la victimización general. En el año 2003 la victimización era en orden al 23,1\%, en circunstancias que el año 2006 (ultimo registro) es de $24,9 \%$. Es decir, de un año al otro existe un aumento porcentual, en tanto, la denuncia para el mismo período refleja una caída considerable. En: http://www.opj.usdoj.gov [visitado el 10.12.2008].

${ }^{36}$ LEVITT, Steven, "Entendiendo por qué se redujo la Criminalidad en la Década de 1990: Cuatro Factores que lo explican y Seis que No", Trad. MATUS, Jean Pierre; VIDAL, Patricio, Ius et Praxis, 2004, vol. 10, $\mathrm{n}^{\circ}$ 2, pp.97-135. En: http://www.scielo.cl/scielo.php?pid=S0718-00122004000200004\&script=sci_a. [visitado el 20.07.2008].
} 
Polit. crim. Vol. 4, No 8 (Diciembre 2009), Art. 5, pp. 430-474 (1-45).

[http://www.politicacriminal.cl/Vol_04/n_08/Vol4N8A5.pdf]

\begin{tabular}{l|ll}
2004 & 3.982 & $-1,9$ \\
2005 & 3.899 & $-2,0$ \\
2006 & 3.808 & $-2,3$ \\
\hline
\end{tabular}

Fuente: Elaboración propia a partir de los datos del UCR, en http://www.fbi.gov/

En materia penológica, la modificación más sustancial, que eventualmente no tendría incidencia en la tasa de denuncias, ocurrió en la década del ochenta al elaborarse las directrices penológicas (sentencing guidelines), cuyo objeto es obtener una determinación de penas de manera uniforme entre los diversos estados federales, pero sólo respecto del derecho penal federal. ${ }^{37}$

\subsubsection{La Situación en España.}

Acercándonos a países de tradición continental, es interesante analizar el caso español, el que, según lo informado por el Ministerio del Interior de dicho país, sobre la base de denuncias realizadas al Cuerpo Nacional de Policía, Guardia Civil y Policía Autónoma Vasca, registra un descenso de la tasa de denuncias en el periodo 1998-2006, de alrededor de un $22 \% .^{38}$

Respecto de estos valores, es necesario precisar e informar al lector que se trabaja con las cifras oficiales emanadas del Ministerio del Interior, las cuales, según se informaría tiempo después en el Anuario Estadístico 2006, mostraría deficiencias en lo que se refiere a las cifras informadas por el Cuerpo de la Guardia Civil en la Comunidad de Madrid y que afectaría el período 2002-2006. Este anuario (2006), corrige el problema y rectifica las cifras. Lamentablemente, la corrección es sólo del año informado y además es global, esto es, se refiere a todos los delitos y faltas, no disponiéndose de un desglose de las infracciones penales por tipología concreta. Esta falta de detalle impide hacer las correcciones necesarias, habida cuenta que sólo trabajo con los DMCS. ${ }^{39}$ No obstante esto,

\footnotetext{
${ }^{37}$ VON HIRSCH, Andrew, Censurar y Castigar, Trad. LARRAURI, Elena, Madrid: Edit. Trotta, 1998, p.13. "La Sentencing Guidelines, se trataba, en definitiva, de elaborar una plantilla; en la línea vertical se reflejarían los diferentes delitos y en la línea horizontal los antecedentes penales. Para cada delito, y en función de los antecedentes, se estipulaba un tiempo determinado de prisión. La plantilla tiene, además, una línea diagonal que establece la demarcación "dentro/fuera", esto es, qué casos recibirían prisión y cuáles una pena distinta de prisión."

${ }^{38}$ En España no se realiza una Encuesta de victimización a nivel nacional. No obstante, el gobierno de la Comunidad Autónoma de Catalunya realiza una encuesta desde el año 1999. En ese año, el índice de victimización alcanzaba al 5,0\%, en circunstancias que el año 2006 es de 7,0\%. En: http://www.gencat.net/interior/ [visitado el 10.12.2008].

${ }^{39}$ Véase el Anuario Estadístico 2006 del Ministerio del Interior. "NOTA IMPORTANTE: Las cifras de infracciones penales conocidas correspondientes al Cuerpo de la Guardia Civil en la Comunidad de Madrid han sido corregidas al alza - y que afecta el período 2002 a 2006 - como resultado de la auditoria recogida en el "INFORME FINAL DEL GRUPO DE TRABAJO PARA EL ESTUDIO DE LA EVOLUCION DELINCUENCIAL EN LA COMUNIDAD DE MADRID EN EL AMBITO DE LA GUARDIA CIVIL", y que fue llevada a cabo por Acuerdo del Comité Ejecutivo para el Mando Unificado (CEMU). Debido a ello, en las tablas donde se recogen los datos totales de delitos y faltas conocidos que corresponden a este Cuerpo, hay que añadirle los datos que en el marginal inferior de las tablas se insertan. Hasta el momento y en referencia a los resultados de dicha auditoria, no se dispone del desglose de las infracciones penales por
} 
SALINERO, Sebastián. "Incidencia de la Probabilidad de Condena en los Delitos de Robo. Análisis Descriptivo y Comparado."

sin restar relevancia al problema, creo que la exposición de estos datos pueden ser útiles para su análisis y arribar a conclusiones que hemos calificado en todo caso como "relativas", máxime, cuando las correcciones oficiales - Ministerio del Interior - las califico en general como poco significativas. En efecto, a manera de ejemplo se informa en el Anuario antes citado, que en el año 2004 debería haberse incrementado el total de infracciones penales en la cantidad de 27.125 casos, ${ }^{40}$ cifra que sumada a la informada originalmente arrojó un universo total de delitos de 2.012.720 casos, es decir, la cantidad corregida fue equivalente sólo a un al 1,34\% de la universalidad de casos.

Dicho lo anterior, la disminución en el caso español, al igual que el estadounidense, puede ser atribuida a diversos factores, entre los cuales destacan, un aumento de los recursos destinados al Ministerio del Interior para combatir la delincuencia y una buena percepción de la ciudadanía sobre la labor de las policías. ${ }^{41}$

El Ministerio del Interior Español destaca que, desde el año 2001 a la fecha, entre el Cuerpo Nacional de Policía y la Guardia Civil, la dotación total de efectivos anotó un incremento del 15\%, registrándose en la actualidad un cuerpo total de $136.258 .{ }^{42}$ A su vez, a lo largo del año 2006, el Cuerpo Nacional de Policía y la Guardia Civil esclarecieron un total de 571.480 delitos y faltas, lo que se traduce en una tasa de esclarecimiento del $30,4 \%$, casi un punto porcentual más que en el año 2005. Dicho valor supone, por un lado, una muy notable mejora de dicha tasa en un $10 \%$ sobre la existente a finales del año 2003 . Y además, y sobre el año 2005, se consigue un incremento en casi dos puntos de la tasa de esclarecimiento de las infracciones más graves, que llega hasta el 36.1\%. Esta mejora de la eficacia policial es particularmente destacada en el esclarecimiento de los delitos, ya que supone un aumento en 8 puntos de la tasa de esclarecimiento de estas infracciones graves, frente a la alcanzada a finales del año $2003(28.1 \%){ }^{43}$

tipología concreta, por lo cual no han podido ser realizadas las correcciones oportunas en las tablas y gráficos correspondientes." (las palabras en mayúscula son de su autor) En: http:/www.mir.es/ [visitado el 25.03.2009]. El Anuario Estadístico 2007 del Ministerio del Interior, no hace mención alguna a los resultados de la auditoria o a eventuales correcciones estadísticas.

Hace años se informaba en el diario El Mundo, publicado el 22 de febrero de 2004, el artículo titulado "Estadísticas Falseadas. Cómo la policía oculta delitos" donde se ofrece referencias y datos de una serie de denuncias presentadas por Juan Manuel López Otero, Inspector Jefe que estuvo adscrito a los servicios de estadística de una comisaría. En 2001, mientras el Ministerio del Interior de España reconocía 1.976.405 delitos y faltas, la Fiscalía General del Estado abría 4.737.173 causas penales. Es decir, los juzgados españoles tramitaron ese año un $239,7 \%$ de denuncias más que las reconocidas en estadísticas presentadas por el Gobierno español. En: http://www.elmundo.es/papel/2004/02/22/cronica/1593125.html [visitado el 20.03.2009]

${ }^{40}$ Conforme al Anuario Estadístico 2006, en el año 2004 se realizo la mayor corrección de casos.

${ }^{41}$ Véase The Burden of Crime in the UE. A Comparative Analysis of the European Crime and Safety Survey 2006. En: http://www.europeansourcebook.org/esb3 Full.pdf [visitado el 08.09.2008].

${ }^{42}$ Véase Policía Española. En http:// www.policia.es. [visitado el 22.08.2008].

${ }^{43}$ Véase La Criminalidad en España en 2006 Avance de Resultados, Ministerio del Interior de España. http://www.mir.es/. [visitado el 22.08.2008]. 
Polit. crim. Vol. 4, No 8 (Diciembre 2009), Art. 5, pp. 430-474 (1-45).

[http://www.politicacriminal.cl/Vol_04/n_08/Vol4N8A5.pdf]

Tabla 3. Evolución en España de la Tasa de Denuncias por cada 100.000 hab. De los denominados Delitos de Mayor Connotación Social entre 1998-2006.

\begin{tabular}{c|cc}
\hline \multicolumn{3}{|c}{ España } \\
\hline Año & Tasa & Variación \\
\hline 1998 & 1.993 & \\
1999 & 1.930 & $-3,1$ \\
2000 & 1.852 & $-4,0$ \\
2001 & 2.056 & +11 \\
2002 & 2.055 & $-0,04$ \\
2003 & 1.841 & $-10,4$ \\
2004 & 1.724 & $-6,3$ \\
2005 & 1.660 & $-3,7$ \\
2006 & 1.546 & $-6,8$ \\
\hline
\end{tabular}

Fuente: Elaboración propia a partir de los datos del Ministerio del Interior de España, en http://www.mir.es/.

Por último, pese a las alentadoras cifras, la investigación empírica ha puesto de manifiesto un fenómeno de indudable preocupación, que se explica en el contexto de lo que se denomina en sociología jurídica y criminología como "sociedad del miedo". Es en este ámbito donde existen instrumentos como las encuestas de victimización, las que permiten medir la actitud de la población ante el delito y de miedo al delito. Estas investigaciones reflejan que desde el año 2000 se ha experimentado en España un notable aumento del miedo al delito (percepción subjetiva del riesgo de ser víctima de un delito) y la preocupación por el delito (opinión de la población respecto a la evolución de la delincuencia en su entorno más cercano), mientras que en el mismo periodo de tiempo, la delincuencia real, medida por la tasa de denuncias, ha permanecido básicamente estable. ${ }^{44}$ Es difícil poder establecer la causa de este fenómeno. ${ }^{45}$ Pero si estamos en condiciones de hipotetizar que, las estadísticas y las encuestas, como instrumentos para medir la delincuencia, son absolutamente dispares, a lo menos, en el ejemplo precedentemente reseñado.

\subsection{Las Condenas.}

Por condena debemos entender la acción y efecto de condenar. Por esta última, debemos inferir el dicho de un juez: pronunciar sentencia, imponiendo al reo la pena

\footnotetext{
${ }^{44}$ TAMARIT, Josep M., "Política criminal con bases empíricas en España”, Polit. crim. no 3 (2007), pp. 1-16, p.13. En http://www.politicacriminal.cl [visitado el 12.08.2008].

${ }^{45}$ Una causa plausible es atribuida a los Medios de Prensa. Véase SOTO NAVARRO, Susana, "La influencia de los medios en la percepción social de la delincuencia." RECPC. 07-09 (2005), pp. 1-46. http://criminet.ugr.es [visitado el 10.12.2008]. En esta misma línea: GARCIA ARAN, Mercedes, Delincuencia, inseguridad y pena en el discurso mediático. En: MUÑOZ CONDE, Francisco (Dir.), Problemas Actuales del derecho Penal y de la Criminología. Estudios penales en memoria de la Profesora Dra. María del Mar Díaz Pita, Valencia: Tirant Lo Blanch, 2008, p. 95.
} 
SALINERO, Sebastián. "Incidencia de la Probabilidad de Condena en los Delitos de Robo. Análisis Descriptivo y Comparado."

correspondiente. En definitiva, la condena la debemos comprender como la declaración de culpabilidad emanada del órgano jurisdiccional y la consiguiente imposición de pena.

\subsubsection{La Situación en Chile.}

En Chile, según la información obtenida desde el Ministerio Público, la tasa de condenas registra en el periodo 2004-2007 un aumento de un 206\%. ${ }^{46}$ Respecto de los años anteriores, esto es: 1998 - 2003, he construido la tasa conforme los datos obtenidos desde el Instituto Nacional de Estadísticas y Fundación Paz Ciudadana, ${ }^{47}$ la cual, experimenta en sus primeros cinco años un comportamiento relativamente análogo, para luego, en el año 2003, evidenciar un aumento considerable, que podría deberse a la reforma procesal penal introducida por Ley $\mathrm{N}^{\mathrm{o}} 19.696 .^{48}$

Tabla 4. Evolución en Chile de las Condenas y de la Tasa de Condenas por cada 100.000 hab. De los denominados delitos de mayor connotación social entre 1998-2007.

\begin{tabular}{c|cc}
\hline \multicolumn{3}{c}{ Chile } \\
\hline Año & Condenas & Tasa \\
\hline 1998 & 12.928 & 86,2 \\
1999 & 13.005 & 85,5 \\
2000 & 13.834 & 89,8 \\
2001 & 14.160 & 90,9 \\
2002 & 13.851 & 87,9 \\
2003 & 19.793 & 124,3 \\
2004 & 23.152 & 143,8 \\
2005 & 36.202 & 222,6 \\
2006 & 55.554 & 338,1 \\
2007 & 73.219 & 441,3 \\
& & \\
\hline
\end{tabular}

Fuente: Elaboración propia a partir de los datos del Ministerio Público, Instituto Nacional de Estadísticas y Fundación Paz Ciudadana. En http://www.ministeriopublico.cl/; $\quad$ http://www.ine.cl.; http://www.pazciudadana.cl.

Creo que el crecimiento de las condenas en los años 2005-2007, pudiese tener como causa plausible, que -en esa época- la reforma procesal penal se encontraba absolutamente interiorizada en la ciudad de Santiago, que individualmente concentra a lo menos el 30\% de

\footnotetext{
${ }^{46}$ Véase http://www.ministeriopublico.cl [visitado el 12.08.2008].

${ }^{47}$ Es necesario hacer presente que, para la construcción de la base de datos sobre las condenas, especialmente en lo relativo al período 1998-2003, recurrimos a los datos ofrecidos por el Instituto nacional de Estadísticas de Chile y La Fundación Paz Ciudadana. Esto, en razón que, por la entrada en vigencia de la reforma procesal penal, el INE (Instituto Nacional de Estadísticas), que era el organismo encargado de recolectar y administrar los datos, utilizaba como fuente de información los antiguos juzgados de letras en lo penal, los cuales, con la reforma, introducida el año 2000, ya no tienen ingresos de causas criminales.

${ }^{48}$ La Ley N 19.696 establece el Código Procesal Penal, fue publicada en el Diario Oficial el 12 de Octubre del año 2000. Tuvo una aplicación gradual, para algunas regiones entró en vigencia desde fines del año 2000 y en la Región Metropolitana recién el 16 de junio del año 2005.
} 
Polit. crim. Vol. 4, No 8 (Diciembre 2009), Art. 5, pp. 430-474 (1-45).

[http://www.politicacriminal.cl/Vol_04/n_08/Vol4N8A5.pdf]

la tasa de denuncias de los DMCS producidos en todo el país, ${ }^{49} \mathrm{y}$ de esa manera, este nuevo proceso penal con acelerados tiempos de enjuiciamiento y un órgano persecutor (Ministerio Público) que hacía su estreno, podrían haber contribuido a lograr las mencionadas cifras. Tampoco descarto, que este hecho pudiese deberse a una razón sistemática en la forma de obtención de la información estadística. Recuérdese que hasta antes de la reforma, el ente encargado de recolectar y administrar los datos era únicamente el Instituto Nacional de Estadísticas, siendo ahora el propio persecutor penal quien los recolecta e informa.

\subsubsection{La Situación en Estados Unidos.}

Tratándose de Estados Unidos, la información obtenida a partir del Departamento de Justicia, Oficina de Estadística, muestra que para el período 1998-2006 se registra un crecimiento en su tasa de condenas de alrededor de un $16 \%$.

Tabla 5. Evolución en Estados Unidos de las condenas y de la tasa de condenas por cada 100.000 hab. De los denominados delitos de mayor connotación social entre los años 1998-2006.

\begin{tabular}{c|cc}
\hline \multicolumn{3}{|c}{ Estados Unidos } \\
\hline Año & Condenas & Tasa \\
\hline 1998 & 803.719 & 295,8 \\
1999 & 844.821 & 315,3 \\
2000 & 827.592 & 292,1 \\
2001 & 841.231 & 293,8 \\
2002 & 868.045 & 299,3 \\
2003 & 898.714 & 307,4 \\
2004 & 961.129 & 325,4 \\
2005 & 997.284 & 334,7 \\
2006 & 1.031 .261 & 342,8 \\
\hline
\end{tabular}

Fuente: Elaboración propia a partir de los datos del Departamento de Justicia de los Estados Unidos, Oficina de Estadísticas (U.S. Department of Justice), en http://www.ojp.usdoj.gov/

El comportamiento de la tasa no es constante al alza. En el año 1999 se observa una variación positiva, la más alta de la primera etapa del período medido. Posteriormente, la tasa decae y a partir del año 2000 presenta un crecimiento sostenido hasta finales de la medición, cercano a un $17 \%$.

\subsubsection{La Situación en España.}

En el caso español, en el período 1998-2006 la tasa no es constante al aumento, ya que presenta variaciones negativas, pero en general es posible afirmar que existe una tendencia al alza. La variación total del período es de un 5,5\%.

\footnotetext{
${ }^{49}$ En la Región Metropolitana, para el año 2007, la tasa total de denuncia de los denominados Delitos de Mayor Connotación Social (DMCS) asciende a 807,4, respecto de una tasa total para todo el país de 2667,7 (cada 100.000 habitantes). En http://www.seguridadciudadana.gov.cl. [visitado el 02.09.2008].
} 
SALINERO, Sebastián. "Incidencia de la Probabilidad de Condena en los Delitos de Robo. Análisis Descriptivo y Comparado."

En los primeros cuatro años de medición, la tasa de condena evidencia una caída de un $23 \%$, para luego, entre los años 2001 y 2004, experimentar un ascenso de un $45 \%$. En el último tramo del período se reporta una variación negativa de aproximadamente un $6 \%$.

Si buscamos las causas probables de la irregularidad del comportamiento de la tasa de condena en la tasa de denuncias previamente analizada, queriendo entender como razonable que a medida que existe mayor denuncia debiese existir mayor condena, se puede plantear como premisa que esta correlación no es correspondida en esos términos. En efecto, en los años 2001 y 2002 la tasa de denuncias fue la más alta del período examinado, en circunstancias que la tasa de condenas para la misma época fue la más baja. Si pensamos, como pudiese parecer corriente, que entre la denuncia y la condena, pasa un tiempo no inferior a seis meses y en ocasiones superior al año, la situación tampoco se aclara, en consideración a que la mayor tasa de condena fue en los últimos tres años del periplo.

Tabla 6. Evolución en España de las Condenas y de la Tasa de Condenas por cada 100.000 hab. De los denominados delitos de mayor connotación social entre 1998-2006

\begin{tabular}{c|cc}
\hline & España \\
\hline Año & Condenas & Tasa \\
\hline 1998 & 52.219 & 130,5 \\
1999 & 46.862 & 116,5 \\
2000 & 44.730 & 110,4 \\
2001 & 41.403 & 100,7 \\
2002 & 44.361 & 106,1 \\
2003 & 52.177 & 122,1 \\
2004 & 63.086 & 146,0 \\
2005 & 58.844 & 133,4 \\
2006 & 61.559 & 137,7 \\
\hline
\end{tabular}

Fuente: Elaboración propia a partir de los datos del Instituto Nacional de Estadísticas, en http://www.ine.es/

\subsection{La Suspensión de la Pena. ${ }^{50}$}

\subsubsection{La Situación en Chile.}

La Ley $\mathrm{N}^{\mathrm{o}} 18.216$ modificó la Ley $\mathrm{N}^{\mathrm{0}} 7.821$ sobre remisión condicional de la pena, que establecía únicamente esta institución, aplicándola básicamente a condenados por delitos de poca gravedad y que presentan escasa peligrosidad.

\footnotetext{
${ }^{50}$ La expresión "Suspensión de la pena", está referida en el caso de Chile sólo a los beneficios contemplados en la Ley N $\mathrm{N}^{\circ} 18.216$ y no a la suspensión condicional del procedimiento prevista en el artículo 237 del Código Procesal Penal. En el caso de Estados Unidos, esta expresión se refiere sólo a la denominada Probation, la cual técnicamente es una suspensión de la sentencia condenatoria. Para España, la expresión alude a la forma sustitutiva de la ejecución de las penas privativas de libertad contemplada en el artículo 80 y siguientes de su código punitivo.
} 


\section{Polit. crim. Vol. 4, № 8 (Diciembre 2009), Art. 5, pp. 430-474 (1-45). \\ [http://www.politicacriminal.cl/Vol_04/n_08/Vol4N8A5.pdf]}

Esta nueva ley incorpora dos nuevas instituciones, además de la existente remisión condicional la que, a pesar de su nombre, es una simple suspensión de la pena. Las nuevas medidas mencionadas son la reclusión nocturna y la libertad vigilada. La primera, consiste en el encierro en centros abiertos, desde las 22 horas de cada día hasta las 6 horas del día siguiente; la segunda consiste, al igual que la remisión condicional, en una suspensión de la ejecución de la pena, pero se diferencia de ella en que lleva consigo un tratamiento intensivo e individualizado en el medio libre.

Como podrá advertirse en la Tabla 7, la medida más utilizada es la remisión condicional, la cual triplica en exceso en su aplicación, con respecto a la medida que la sigue. Los requisitos para que el tribunal pueda concederla están establecidos en el artículo $1^{\mathrm{o}}$ de la citada ley. Fundamentalmente, se refieren a que la sentencia debe imponer una pena restrictiva o privativa de libertad no superior a cierta duración la que en la ley original era de un año, y que en la actualidad es de tres; que el reo no haya sido condenado anteriormente por crimen o simple delito, y que los antecedentes personales del reo y su conducta anterior, la naturaleza, modalidades y móviles determinantes del delito, permitan presumir que no volverá a delinquir. ${ }^{51}$

Si el tribunal concede la remisión condicional de la pena, debe someter al reo a un plazo de observación y establecer diversas condiciones que éste deberá cumplir y que consisten en la obligación de residencia en un lugar determinado; la sujeción a la vigilancia de alguno de los Patronatos de Reos; la adopción de una profesión, oficio, empleo o comercio, y la satisfacción de las responsabilidad civil, costas y multas impuestas por la sentencia.

Por su parte, para la concesión de la reclusión nocturna que, dicho sea de paso, es la medida contemplada en la ley con menos utilización por parte del operario jurisdiccional penal, y que es aplicable tanto a primarios como a reincidentes, han de cumplirse los siguientes requisitos: que el reo haya sido condenado a una pena privativa o restrictiva de libertad que no exceda de dos años o a más de una, siempre que en total no excedan de dicho límite; los antecedentes personales del reo y su conducta anterior y posterior al hecho punible y la naturaleza, modalidades y móviles determinantes del delito permitan presumir que la medida lo disuadirá de cometer nuevos delito.

El Título II de la ley contempla una de las medidas alternativas más importantes, de amplia difusión en otros países: la libertad vigilada o a prueba. ${ }^{52}$ Los requisitos para su otorgamiento son: una pena privativa o restrictiva de libertad superior a dos años y que no exceda de cinco; que el reo sea primario y que, de acuerdo a informes sobre antecedentes sociales y características de personalidad, pueda concluirse que en el caso especifico un

\footnotetext{
${ }^{51}$ La ley $\mathrm{N}^{\mathrm{o}} 17.642$ introdujo importantes modificaciones a la ley $\mathrm{N}^{\mathrm{o}}$ 7.821, amplió a 3 años el límite máximo de las penas privativas y restrictivas de libertad para ser susceptibles de remisión, el que como se dijo, originalmente era de un año, fijando como plazo de observación, el doble del tiempo de la pena que se haya impuesto, sin que pueda ser inferior a un año ni superior a cinco. Para más información sobre la Ley $\mathrm{N}^{\circ}$ 18.216, véase Fundación Paz Ciudadana. HOFER, María Eugenia, “Medidas alternativas a la reclusión”. En: http://www.pazciudadana.cl/docs/pub_20090519144838.pdf. [visitado el 12.11.2009].

${ }^{52}$ La expresión "a prueba" es utilizada conforme a las actas de instauración de la ley, por el Secretario de Legislación de la Junta de Gobierno y Comisión Legislativa, durante la dictadura de Pinochet.
} 
SALINERO, Sebastián. "Incidencia de la Probabilidad de Condena en los Delitos de Robo. Análisis Descriptivo y Comparado."

tratamiento en libertad aparece como eficaz y necesario para una efectiva readaptación y resocialización del hechor.

El plazo de tratamiento y observación no será inferior al de duración de la pena, con un mínimo de tres años y un máximo de seis.

Entre las condiciones que debe cumplir el reo se encuentran, la obligación de residencia en un lugar determinado; la adopción de una profesión, oficio, empleo o comercio. La más importante, eso sí, es aquella que otorga la esencial característica a esta institución, es la de someter al condenado a la vigilancia y orientación permanentes de un delegado que impartirá normas de conducta e instrucciones sobre educación, trabajo, morada, cuidado del núcleo familiar, empleo del tiempo libre y toda otra que sea pertinente a un eficaz tratamiento en libertad.

Los Tribunales con competencia en lo penal, cumplidos los requisitos legales, tienen la potestad, conforme a la ley $\mathrm{N}^{\mathrm{o}} 18.216$, de suspender condicionalmente la ejecución de la pena privativa de libertad, o bien, decretar una pena alternativa a la prisión propiamente tal. ${ }^{53}$ Son medidas que suspenden condicionalmente la ejecución de penas privativas de libertad: la remisión condicional de la pena y la libertad vigilada; y es una pena alternativa a la prisión: la reclusión nocturna. Estos beneficios a favor del reo son conocidos en su conjunto como medidas alternativas al cumplimiento de las penas privativas de libertad.

En Chile, las medidas alternativas al cumplimiento de las penas privativas de libertad, previstas en la ley $\mathrm{N}^{\mathrm{o}}$ 18.216, han mostrado un crecimiento desde su entrada en vigencia, acaecida el 14 de mayo de 1983.

En el período indicado en la Tabla 7, las medidas en su totalidad o el total Ley № 18.216 refleja una variación positiva de la tasa en orden al 30,4\%, lo que denota su aparente uso masivo por los Tribunales encargados de ejercer competencia penal. La variación de la tasa no fue positiva en todo el período de muestra, siendo negativa entre los años 2000-2005, alcanzando una caída de alrededor de un 21\%. La razón probable de esta tendencia negativa, la atribuyo al indulto general, consagrado en la Ley $\mathrm{N}^{\mathrm{o}} 19.736^{54}$ del año 2001,

\footnotetext{
${ }^{53}$ POLITOFF, Sergio; MATUS, Jean Pierre; RAMIREZ, María Cecilia, Lecciones de Derecho Penal. Parte General, 2 ${ }^{a}$ Ed., Santiago: Editorial Jurídica, 2006, p. 543, quienes señalan: "La suspensión de la ejecución de la pena privativa de libertad, no constituyen penas autónomas diferentes a la prisión, sino formas de suspensión condicional de la pena privativa de libertad, cuyo incumplimiento acarrea necesariamente la imposición de la pena privativa de libertad primitivamente impuesta. En cambio, las penas alternativas a la prisión propiamente tales, se plantea como penas principales excluyentes de la pena de prisión, en los casos de mediana y baja gravedad, de modo que su imposición no es condición para no cumplir una pena privativa de libertad, por lo que su incumplimiento no se encuentra amenazado con la imposición de la pena privativa de libertad suspendida condicionalmente".

${ }^{54}$ La Ley 19.736 sobre Indulto General, con motivo del Jubileo del 2000, fue publicada en el D.O. el 19 de julio del año 2001. Concede un indulto general, en la forma que expresa, a los condenados por sentencia ejecutoriada que a la fecha de publicación de esa ley, estuvieren cumpliendo efectivamente sus penas, en libertad condicional o acogidos a algunos de los beneficios contemplados en la ley 18.216. Respecto de los que estuvieren cumpliendo penas efectivas, favoreció a los condenados por sentencia ejecutoriada a penas privativas o restrictivas de libertad con una duración igual o inferior a 5 años, reduciéndoseles a dos meses por cada año que debiesen purgar.
} 
Polit. crim. Vol. 4, № 8 (Diciembre 2009), Art. 5, pp. 430-474 (1-45).

[http://www.politicacriminal.cl/Vol_04/n_08/Vol4N8A5.pdf]

cuyo origen se debe a una petición de la Iglesia Católica en el marco de la conmemoración del Jubileo del año 2000, que favoreció a los presos no peligrosos y a los que hubiesen cometido delitos menores. También, es interesante analizar el notable aumento de la tasa de suspendidos para el año 2007, la cual tuvo una variación del 34,1\% respecto del año anterior. Una hipótesis probable que explique este crecimiento, la encontramos en el hecho que para el mismo período (2006-2007) la tasa de condena creció en un 30,5\%. Es decir, a mayor tasa de suspendidos, hubo mayor tasa de condenas o viceversa.

Además, cabe evidenciar al lector que en dicha frecuencia de tiempo, en que la variación de la suspensión de la pena fue negativa, la tasa de denuncias de los DMCS reportó los comportamientos positivos más altos de este estudio. Así, por ejemplo, la variación de la tasa de denuncias para los años 2000-2005 fue de $+57,5 \%$, en circunstancias que la tasa de suspensión de la pena para el mismo periplo fue de un $-21,2 \% .{ }^{55}$

Tabla 7. Evolución en Chile de Número de Personas y Tasa por cada 100.000 hab. de Medidas Alternativas entre 1998-2007.

\begin{tabular}{|c|c|c|c|c|c|c|c|c|}
\hline \multirow{2}{*}{ AÑO } & \multicolumn{2}{|c|}{ REC. NOCTURNA } & \multicolumn{2}{|c|}{$\begin{array}{c}\text { REM. } \\
\text { CONDICIONAL }\end{array}$} & \multicolumn{2}{|c|}{ LIB. VIGILADA } & \multicolumn{2}{|c|}{ TOTAL LEY 18.216} \\
\hline & $\mathrm{N}^{\circ}$ PERSONAS & TASA & $\mathrm{N}^{\circ}$ PERSONAS & TASA & $\mathrm{N}^{\circ}$ PERSONAS & TASA & $\mathrm{N}^{\circ}$ PERSONAS & TASA \\
\hline 1998 & 1.349 & 9,0 & 25.436 & 169,6 & 3.584 & 23,9 & 30.369 & 202,5 \\
\hline 1999 & 1.511 & 9,9 & 26.274 & 172,9 & 4.028 & 26,5 & 31.813 & 209,3 \\
\hline 2000 & 1.700 & 11,0 & 26.537 & 172,3 & 3.462 & 22,5 & 31.699 & 205,9 \\
\hline 2001 & 1.812 & 11,6 & 25.507 & 163,8 & 3.494 & 22,4 & 30.813 & 197,9 \\
\hline 2002 & 1.785 & 11,3 & 23.509 & 149,3 & 3.445 & 21,9 & 28.739 & 182,5 \\
\hline 2003 & 1.755 & 11,0 & 23.138 & 145,3 & 3.694 & 23,2 & 28.587 & 179,6 \\
\hline 2004 & 1.690 & 10,5 & 21.550 & 133,9 & 4.355 & 27,1 & 27.595 & 171,5 \\
\hline 2005 & 1.816 & 11,2 & 19.223 & 118,2 & 5.330 & 32,8 & 26.369 & 162,1 \\
\hline 2006 & 3.115 & 19,0 & 22.413 & 136,4 & 6.816 & 41,5 & 32.344 & 196,8 \\
\hline 2007 & 4.488 & 27,0 & 30.569 & 184,2 & 8.772 & 52,8 & 43.829 & 264,1 \\
\hline
\end{tabular}

Fuente. Elaboración propia de los datos obtenidos del Ministerio del Interior de Chile. División Seguridad Pública.

\subsubsection{La Situación en Estados Unidos.}

Probation es la suspensión de la totalidad o parte de una sentencia que condena a una persona a una pena de cárcel. El culpable de un delito, en lugar de servir tiempo en la cárcel, queda en una especie de libertad vigilada y será devuelto a la comunidad por un período en el que tendrá que atenerse a ciertas condiciones establecidas por la Corte, bajo la supervisión de un agente de libertad (probation officer). Tales condiciones generales

\footnotetext{
${ }^{55}$ Esto puede explicarse teniendo en cuenta que, en casos de reincidencia no se concede el beneficio: si hay más denuncias puede haber más reincidentes $\mathrm{y}$, por lo tanto, menos eventuales condenados susceptibles de ver suspendida la pena.
} 
SALINERO, Sebastián. "Incidencia de la Probabilidad de Condena en los Delitos de Robo. Análisis Descriptivo y Comparado."

pueden incluir, el mantenimiento del empleo, respetar un toque de queda, la prohibición de salir de un determinado distrito y la abstención de contacto con otras personas, que pueden incluir las víctimas del delito original, como una ex-pareja en los casos de violencia doméstica, y las posibles víctimas de crímenes similares, como los menores de edad cuando el delito implica el abuso sexual infantil. En algunos casos el delincuente en libertad está provisto de una etiqueta electrónica, la que señala a sus supervisores su paradero exacto.

Por lo general, el delincuente es supervisado por un agente de libertad, a fin de vigilar su desempeño durante el período de prueba. El agente de libertad ayuda al delincuente para adaptarse a vivir en la comunidad, para orientar y ayudar a comportarse de manera legal y responsable. Además, aquel supervisa al delincuente para garantizar que en el futuro no vuelva a cometer un delito. Es por esto que este funcionario tiene la facultad de solicitar que se revoque la libertad concedida.

De lo expuesto en la Tabla 8, vemos que la probation tiene un comportamiento positivo, mostrando un crecimiento de su tasa en el período observado de un 11,9\%. Pese a esto, la variación de la tasa es irregular, es así como por ejemplo en el año 1999 presenta su indicador más alto, para luego disminuir y manifestar un alza hasta el año 2004. Después, en el año 2005 vuelve a disminuir y comienza un nuevo comportamiento positivo.

Tabla 8. Evolución en Estados Unidos del Número de Personas y Tasa por cada 100.000 hab. de Probation entre 1998-2006.

\begin{tabular}{c|cc}
\hline \multicolumn{3}{|c}{ PROBATION } \\
\hline Año & $\mathrm{N}^{\mathrm{o}}$ Personas & Tasa \\
\hline 1998 & 3.417 .613 & 1258 \\
1999 & 3.773 .624 & 1409 \\
2000 & 3.839 .532 & 1351 \\
2001 & 3.932 .751 & 1373 \\
2002 & 3.995 .165 & 1388 \\
2003 & 4.073 .987 & 1393 \\
2004 & 4.143 .466 & 1403 \\
2005 & 4.162 .536 & 1398 \\
2006 & 4.237 .023 & 1408 \\
\hline
\end{tabular}

Fuente: Elaboración propia a partir de los datos del Departamento de Justicia de los Estados Unidos, en http://www.ojp.usdoj.gov/bjs/pandp.htm

\subsubsection{La Situación en España.}

El Código Penal Español de 1995, regula en su artículo 80 y siguientes, la posibilidad de la magistratura de suspender fundadamente una pena privativa de libertad. ${ }^{56}$ La sentencia

\footnotetext{
56 Artículo 80: "Los jueces o tribunales podrán dejar en suspenso la ejecución de las penas privativas de libertad, no superiores a dos años, mediante resolución motivada. En dicha resolución se atenderá fundamentalmente a la peligrosidad criminal del sujeto, así como a la existencia de otros procedimientos penales contra éste. 2. El plazo de suspensión será de dos a cinco años para las penas privativas de libertad
} 
Polit. crim. Vol. 4, № 8 (Diciembre 2009), Art. 5, pp. 430-474 (1-45).

[http://www.politicacriminal.cl/Vol_04/n_08/Vol4N8A5.pdf]

condenatoria, además de la declaración de culpabilidad, impone una pena, quedando ésta en suspenso mientras se cumplan, en un plazo de prueba, varias condiciones, además de una serie de reglas de conducta a cargo del sujeto beneficiado.

Son requisitos para el otorgamiento de la suspensión, que la sentencia imponga una pena de prisión de hasta dos años, que el beneficiado no haya sido condenado con anterioridad y que haya solucionado las responsabilidades civiles, salvo declaración contraria del juez de la causa. ${ }^{57}$

El plazo de suspensión puede fijarse desde los dos hasta los cinco años, período de prueba que el juez o tribunal deberá fijar en su resolución según la gravedad de la pena suspendida.

Tabla 9. Evolución en España del Número de Personas y Tasa por cada 100.000 hab. de Suspensión de la Pena entre 1997-2005.

\begin{tabular}{c|cc}
\hline \multicolumn{3}{c}{ SUSPENSION DE LA PENA } \\
\hline Año & $\mathrm{N}^{\mathrm{o}}$ Personas & Tasa \\
\hline 1997 & 10.102 & 25 \\
1998 & 10.180 & 25 \\
1999 & 11.406 & 28 \\
2000 & 14.763 & 36 \\
2001 & 20.677 & 50 \\
2002 & 26.716 & 65 \\
2003 & 34.638 & 81 \\
2004 & 51.894 & 120 \\
2005 & 54.576 & 124 \\
\hline
\end{tabular}

Fuente: Elaboración propia a partir de los datos del Instituto Nacional de Estadísticas, Ministerio del Interior de España y los datos obtenidos de otros autores, en http://www.ine.es/ y http://www.mir.es/

Conforme a la Tabla 9, la suspensión de la pena tiene un comportamiento positivo, mostrando un crecimiento de su tasa en el período 1997-2005 de un 380\%. Cabe hacer presente que, la progresión es ascendente, regular y no registra descensos en intervalo alguno de la etapa controlada. ${ }^{58}$

inferiores a dos años, y de tres meses a un año para las penas leves; y se fijará por los Jueces o Tribunales, previa audiencia de las partes, atendidas las circunstancias personales del delincuente, las características del hecho y la duración de la pena. 3. La suspensión de la ejecución de la pena no será extensiva a la responsabilidad civil derivada del delito o falta penados.4. Los Jueces y Tribunales sentenciadores podrán otorgar la suspensión de cualquier pena impuesta, sin sujeción a requisito alguno en el caso de que el penado esté aquejado de una enfermedad muy grave con padecimientos incurables, salvo que en el momento de la comisión del delito tuviera ya otra pena suspendida por el mismo motivo".

${ }^{57}$ Excepcionalmente el artículo 87 del Código Penal español, permite la suspensión de una pena de prisión de tres años, cuando el delito se ha cometido como consecuencia de una grave dependencia de las drogas. Este derecho no puede ser impetrado en caso de reincidencia por parte del drogodependiente.

${ }^{58}$ Cid Moliné ha obtenido datos no publicados, suministrados por el Registro central de penados y rebeldes. Según ellos, el porcentaje de penas privativas de libertad registradas como suspendidas, frente al total de las 
SALINERO, Sebastián. "Incidencia de la Probabilidad de Condena en los Delitos de Robo. Análisis Descriptivo y Comparado."

\subsection{La Población Penal. ${ }^{59}$}

\subsubsection{La Situación en Chile.}

Según las estadísticas de Gendarmería de Chile, a partir de 1993 la población penal ha experimentado un crecimiento constante. Esto se puede deber a una política de indultos restringidos, a la disminución en el otorgamiento de la libertad provisional por parte de los tribunales y al mayor ingreso de individuos al sistema penitenciario, producto de una mayor eficiencia en la labor de las policías, o a una combinación de algunas o todas las anteriores circunstancias. Según el Centro de Estudios de Justicia de las Américas, lo anterior se tradujo en tasas de crecimiento promedio anual de 6,5\% entre 1995 a 2000, llegando a variaciones anuales de 12\% (medida entre diciembre de 1998 y diciembre de 1999). Esta sobrepoblación se vio agravada, además, por el mayor volumen de condenados en el sistema, luego de la entrada en vigencia de la reforma procesal penal en la Región Metropolitana (Santiago). ${ }^{60}$

Tabla 10. Evolución en Chile del Número de Personas y de la Tasa de Reclusos cada 100.000 hab. ${ }^{61}$

\begin{tabular}{cc|cc}
\hline \multicolumn{3}{c}{ Chile } \\
\hline Año & N $^{\circ}$ Personas & Tasa \\
\hline 1998 & 26.871 & 179 \\
1999 & 30.051 & 198 \\
2000 & 33.050 & 215 \\
2001 & 33.620 & 216 \\
2002 & 34.901 & 222 \\
2003 & 36.331 & 228 \\
2004 & 36.374 & 226 \\
2005 & 37.033 & 228 \\
2006 & 39.417 & 240 \\
2007 & 43.602 & 263 \\
\hline
\end{tabular}

Fuente: Ministerio del Interior. División de Seguridad Pública.

registradas se está incrementando aceleradamente desde 1998: Si en esa fecha se registraban como suspendidas el 10,6\% de todas las penas de prisión registradas, tres años más tarde el porcentaje se había duplicado 20,8\%, volviéndose a más que duplicar en los dos años siguientes, de forma que, en 2003 las penas de prisión suspendidas registradas suponían el 44,1\% de todas las penas de prisión registradas. CID MOLINE, José, "La suspensión de la pena en España: descarcelación y reincidencia", Revista de derecho penal y criminología, (2005), pp. 230-231. Citado en: DIEZ RIPOLLES, José Luis, "La evolución del sistema de penas en España: 1975-2003.” RECPC., 08-07 (2006), pp. 1-25, p. 19.

${ }_{59}$ Para el caso de los tres comparados, debemos entender por "Población penal" todas aquellas personas que cumplen una pena privativa de libertad en régimen cerrado.

${ }^{60}$ Véase Reporte sobre la Justicia en las Américas 2005-2006. Centro de Estudios de Justicia de las Américas, CEJA. En http:// www.cejamericas.org/ [visitado el 18.08.2008].

${ }^{61}$ Corresponde a todos aquellos personas privadas de libertad y que pernoctan en las Unidades Penales, en este sistema se encuentran los Detenidos, Procesados (antiguo sistema penal), Imputados (nuevo sistema penal) y los condenados privados de libertad ( no se incluyen los que tienen Medidas alternativas o se encuentran con pena suspendida) 
Polit. crim. Vol. 4, № 8 (Diciembre 2009), Art. 5, pp. 430-474 (1-45).

[http://www.politicacriminal.cl/Vol_04/n_08/Vol4N8A5.pdf]

Para el período expuesto en la Tabla 10, la población penal ha crecido de manera uniforme, experimentado una variación de un $47 \%$.

En el contexto latinoamericano, según el Centro de Estudios de Justicia de las Américas, las diferentes cifras concuerdan en que Chile es el Estado que cuenta con un mayor número de reclusos por cada cien mil habitantes (con una tasa superior de doscientos veintiséis presos en el año 2004), supera al resto de los países que conforman la región. En efecto, Brasil cuenta con una tasa de ciento ochenta y siete; México, ciento ochenta y tres; Argentina, ciento setenta y tres. ${ }^{62}$

Teóricamente, un aumento en el encarcelamiento produciría tanto incapacitación en quienes se encuentran tras las rejas, como un estímulo para disuadir a la comisión de los delitos, recibido por quienes observan el fenómeno. Esta teorización se encuentra respaldada con consistentes estudios empíricos (Donohue, 2005) (3) $^{6}$ y encuestas a reclusos en Estados Unidos (DiLulio y Piehl 1991). ${ }^{64}$

Para el caso chileno, aparentemente, el aumento de la población penal no trae como consecuencia una disminución de la tasa de denuncia. Ambas variables se comportan de manera positiva, de modo tal que, si aumenta una, aumenta la otra, haciéndolo prácticamente en la misma proporción. De una probable lectura, podemos sostener dos posibles hipótesis: que la cárcel no disuade en los términos esperados y pregonados por el profesor Levitt, ${ }^{65}$ o a lo mejor, se reafirma la tesis en el sentido de sostener que si no existiesen los niveles actuales de encarcelamiento la tasa de denuncia sería incluso mayor.

El por qué del crecimiento de la población penal en Chile puede obedecer a un sin número de factores. Estableciendo una hipótesis al respecto, la que debe ser objeto de un estudio más lato y acucioso, la puedo reducir a que el aumento en el flujo de ingresos a las cárceles y una disminución de los egresos, puede deberse a las largas condenas que cumplen los reclusos y una política restrictiva de beneficios penitenciarios. ${ }^{66}$ Para tener una certeza y resolver esta interrogante, se debería realizar un estudio estadístico de flujo carcelario, el cual, pese a mi intención de abarcar con la agudeza necesaria el problema, no cuento con

\footnotetext{
${ }^{62}$ Véase Reporte sobre la Justicia en las Américas 2004 -2005, Centro de Estudios de Justicia de las Américas, CEJA. En http:// www.cejamericas.org/ [visitado el 18.08.2008].

${ }^{63}$ Véase DONOHUE, John, "Fighting Crime: An Economist's View", The Milken Institute Review, 7 n 46 (2005), pp. 46 -58. En: http://works.bepress.com/cgi/viewcontent.cgi?article=1016\&context=john donohue. [visitado el 20.03.2009].

${ }^{64}$ Véase DILULIO, John; PIEHL, Ann, "Does Prison Pay? The Stormy National Debate Over the CostEffectiveness of Imprisonment", Brookings Review, (1991), 28-35.

${ }^{65}$ LEVITT, "Entendiendo", cit. nota $n^{\circ}$ 36. También en: LEVITT, "Using electoral Cycles in police hiring to estimate the effects of police on crime", American Economic Review, Vol. 87, n ${ }^{\circ} 3$ (1997), pp. 270-290. Cf.: MATUS, Jean Pierre, “ ¿Por qué no bajan las Tasas de Criminalidad en Chile?”, Revista de Derecho de la P. U. Católica de Valparaíso, XXVI Valparaíso (2005), Semestre I, pp.67-92, p.84. La hipótesis del profesor Steven Levitt señala que el encarcelamiento producirá tanto incapacitación en quienes se encuentren tras las rejas, como un estímulo para disuadir a la comisión de los delitos.

${ }^{66}$ Cfr. FREY VALDES, Antonio, "Población Penal y Mercado Laboral: Un Modelo Empírico para el período 1982-2002 en la Región Metropolitana". Manuscrito facilitado por su autor.
} 
SALINERO, Sebastián. "Incidencia de la Probabilidad de Condena en los Delitos de Robo. Análisis Descriptivo y Comparado."

los datos necesarios y no estoy en condiciones de realizar en este estudio, por los tiempos que ese cometido requiere.

\subsubsection{La Situación en Estados Unidos.}

En el caso comparado de Estados Unidos la tendencia es similar a la chilena, esto es, existe un aumento de la población penal. El período analizado registra un alza en la tasa torno al $12,2 \%$.

Este enorme crecimiento de la tasa, que empezó a experimentarse según Levitt en la década del noventa, puede ser atribuido a un sin número de factores, entre los que destacan, el gran aumento de los encarcelamientos por delitos relacionados con droga, el aumento de la revocación de la libertad bajo palabra, y la imposición de sentencias más larga para los acusados (Kuziemko y Levitt 2003). ${ }^{67}$

Tabla 11. Evolución en Estados Unidos del Número de Personas y Tasa de Reclusos cada 100.000 hab. ${ }^{68}$

\begin{tabular}{c|cc}
\hline \multicolumn{3}{|c}{ Estados Unidos } \\
\hline Año & $\mathrm{N}^{\mathrm{o}}$ Personas & Tasa \\
\hline 1998 & 1.817 .272 & 669 \\
1999 & 1.851 .062 & 691 \\
2000 & 1.937 .482 & 684 \\
2001 & 1.961 .247 & 685 \\
2002 & 2.033 .022 & 701 \\
2003 & 2.081 .580 & 712 \\
2004 & 2.135 .335 & 723 \\
2005 & 2.195 .873 & 737 \\
2006 & 2.258 .983 & 751 \\
\hline
\end{tabular}

Fuente: Departamento de Justicia de los Estados Unidos. En http://www.ojp.usdoj.gov/

Otro ejemplo importante de mencionar, que cuenta con importante sustento empírico, es lo sucedido en el Estado de California, en que el crecimiento de la población penal es atribuido a la regla introducida en los años setenta, conocida como three strikes and you are out (expresión utilizada en el baseball para indicar que el bateador que no golpea válidamente la pelota tres veces pierde su turno de bateo). ${ }^{69}$ En virtud de esta regla, el sujeto

${ }^{67}$ LEVITT, "Entendiendo", cit. nota n o 36. Para un estudio más acabado, véase: KUZIEMKO, Ilyana; LEVITT, Steven, "An empirical analysis of imprisoning drug offenders", Journal of Public Economics, Elsevier, vol. 88 (2004), pp. 2043-2066.

${ }^{68}$ Corresponde a todas aquellas personas privadas de libertad en Unidades Penales federales o estaduales, en este sistema se encuentran los Detenidos (Jail) que esperan un juicio, una sentencia, o sirven una pena inferior a un año, o esperan ser trasladados a otro recinto penal. También se incluyen los condenados privados de libertad (no se incluyen los que tienen una pena suspendida (probation) o en libertad condicional (parole)).

${ }^{69}$ Véase: ZIMRING, Franklin; HAWKINS, Gordon; KAMIN, Sam, "Punishment and Democracy. Three strikes and you're out in California", New York, (2001). En: CHAZARRA QUINTO, Maria Asunción, "La Reincidencia en el Código Penal Español: Una mirada al controvertido modelo norteamericano", Revista 
Polit. crim. Vol. 4, № 8 (Diciembre 2009), Art. 5, pp. 430-474 (1-45).

[http://www.politicacriminal.cl/Vol_04/n_08/Vol4N8A5.pdf]

que vuelve a cometer un tercer delito, aunque sea de escasa relevancia (por ejemplo, un hurto), después de haber cometido anteriormente dos graves (no necesariamente violentos, por ejemplo un robo en casa habitada), debe ser castigado con una pena de prisión perpetua o de veinticinco años mínimo, sin posibilidad de reducción. ${ }^{70}$

\subsubsection{La Situación en España.}

La población penal en el caso español tiene un comportamiento positivo, mostrando un crecimiento de su tasa en el período analizado de un 26,6\%. La evolución de la tasa en el período no es crónica al ascenso, toda vez que en el año 2000 experimentó una caída en un punto, para luego, de manera uniforme tender al alza constante.

Tabla 12. Evolución en España del Número de Personas y Tasa de reclusos cada 100.000 hab. ${ }^{71}$

\begin{tabular}{c|cc}
\hline \multicolumn{3}{|c}{ España } \\
\hline Año & $\mathrm{N}^{\mathrm{o}}$ Personas & Tasa \\
\hline 1997 & 43.452 & 109 \\
1998 & 44.747 & 112 \\
1999 & 45.406 & 113 \\
2000 & 45.309 & 112 \\
2001 & 46.594 & 113 \\
2002 & 50.109 & 121 \\
2003 & 54.465 & 128 \\
2004 & 58.655 & 136 \\
2005 & 60.707 & 138 \\
\hline
\end{tabular}

Fuente: Instituto Nacional de Estadísticas de España.

electrónica Derecho Penal On Line, Septiembre $\quad$ (2007),
http://www.derechopenalonline.com/derecho.php?id=13,427,0,0,1,0 [visitado el 20.03.2009].

El estado norteamericano de California posee el complejo carcelario más grande del mundo después de China y los Estados Unidos en su conjunto, una buena muestra de ello es que entre los años 1984 y 2001 se han construido en este estado 21 prisiones. Se calcula que en el año 2010 la población penitenciaria en California puede alcanzar los 180.000 reclusos. De1,2 millones de personas actualmente encarceladas en Estados Unidos 1 de cada 9 están cumpliendo condena en el Estado californiano. Véase: HARRISON, Paige; BECK, Allen, "Prison and Jail Inmates at Midyear 2004", Bureau of Justice Statistics, U.S. Department of Justice, April (2005). En: http://www.ojp.usdoj.gov/ [visitado el 20.03.2009]

${ }^{70}$ HASSEMER, Winfried; MUÑOZ CONDE, Francisco, Introducción a la Criminología. Valencia: Edit. Tirant Lo Blanch, 2001, p.288. La aplicación de dicha política ha provocado un aumento de la conflictividad en las cárceles y de los gastos de mantenimientos de los mismos, así como una mayor necesidad de policías, jueces, funcionarios, etc. Ofrecen un amplio análisis de las leyes "three strikes" y del debate en torno a su constitucionalidad en: CASTIÑEIRA, María Teresa; RAGUÉS, Ramón, "Three Strikes. El principio de proporcionalidad en la jurisprudencia del Tribunal Supremo de los Estados Unidos", RDPCrim., $2^{\mathrm{a}}$ época, $\mathrm{n}^{\circ}$ 14 (2004), pp. 59-85.

${ }^{71}$ Corresponde a todas aquellas personas privadas de libertad en Unidades Penales, en este sistema se encuentran los detenidos en prisión preventiva y los condenados que sirven una pena privativa de libertad. 
SALINERO, Sebastián. "Incidencia de la Probabilidad de Condena en los Delitos de Robo. Análisis Descriptivo y Comparado."

En el caso español, el profesor José Cid en una monografía titulada "El incremento de la población reclusa en España entre 1996-2006. Diagnóstico y Remedio"72 atribuye el incremento de la población penal al endurecimiento de las penas, consagrado por el Código Penal de 1995. Igual afirmación realiza el profesor Josep M. Tamarit quien, además, agrega como causa probable la presión del sistema penal sobre los extranjeros, que han pasado a significar en 2006 el 29,7 \% de la población reclusa. ${ }^{73}$

\subsection{Conclusiones.}

De una revisión de los datos recopilados en Chile, España y Estados Unidos, en relación a los comportamientos de las tasas de denuncia, condenas, suspensión de la pena y población penal se puede extraer, a través de un estudio comparativo, las siguientes conclusiones:

Mientras España y Estados Unidos muestran un comportamiento negativo y sostenido en el tiempo de medición de la tasa de denuncias como proxy de la criminalidad, Chile tiene una variación positiva, exponiendo un crecimiento por sobre el $+115 \%$ en el periodo analizado.

Tratándose de la tasa de condenas, se puede decir que todos los informados presentan un comportamiento positivo. Sin duda, el crecimiento de un $+411 \%$ en Chile es mayor que el de los comparados. Esto es probable que se deba, a la creación del Ministerio Público, a una nueva política criminal de mayor persecución y, en general, a la entrada en vigencia de manera gradual de la reforma procesal penal.

Con respecto a la suspensión de la pena, los comparados, en términos generales, presentan un crecimiento en su tasa para el período medido. No obstante, Chile en el período 19992005 presenta una variación negativa de $-21 \%$, para luego tener una tendencia positiva.

La población penal es la más fácil de analizar. Todos los comparados presentan en el periodo observado un crecimiento constante. Chile presenta una variación positiva de $+47 \%$ en el tiempo analizado.

\section{Correlación de variables.}

En sentido estricto, la correlación entre dos variables tan solo significa que ambas comparten información, que comparten variabilidad. Determinar el origen de la información, la fuente de la variabilidad, la causa, es una cuestión que no puede resolverse mediante recursos exclusivamente matemáticos.

Para realizar la correspondencia utilizare el coeficiente de correlación de Pearson. La correlación entre dos variables refleja el grado en que las puntuaciones están asociadas.

\footnotetext{
${ }^{72}$ CID MOLINE, José, “El incremento de la población reclusa en España entre 1996-20006. Diagnostico y Remedio". Revista Española de Investigación Criminológica, Artículo 2, № 6 (2008), pp. 1-31. Por su parte, el profesor Díez Ripolles coincide que con la entrada en vigencia del Código Penal de 1995 las penas de corta duración y de multa presentan una significativa reducción. En cambio, las penas medias y largas de prisión, presentan un marcado ascenso. DIEZ RIPOLLES, José Luis, "La evolución del sistema de", cit. nota $\mathrm{n}^{\circ}$ 58, pp. $1-25$, p. 18.

${ }^{73}$ TAMARIT, "Política criminal”, cit. nota ${ }^{\circ}$ 44, p. 7.
} 
Polit. crim. Vol. 4, No 8 (Diciembre 2009), Art. 5, pp. 430-474 (1-45).

[http://www.politicacriminal.cl/Vol_04/n_08/Vol4N8A5.pdf]

Este tipo estadístico puede utilizarse para medir el grado de relación de dos variables si ambas utilizan una escala de medida a nivel de intervalo.

Para el procedimiento de correlación, como se dijo anteriormente al referirse a la metodología empleada en este trabajo, ${ }^{74}$ en la variable denuncia, por sus características especiales se optó tener como indicador o proxy al robo con fuerza. Además, se optó por tener una variable control, el robo con violencia.

El valor del índice de correlación varía en el intervalo $[-1,+1]$ y se expresa con la letra "R":

- Si $\mathrm{r}=0$, no existe ninguna correlación. El índice indica, por tanto, una independencia total entre las dos variables, es decir, que la variación de una de ellas no influye en absoluto en el valor que pueda tomar la otra.

- Si $\mathrm{r}=1$, existe una correlación positiva perfecta. El índice indica una dependencia total entre las dos variables denominada relación directa: cuando una de ellas aumenta, la otra también lo hace en idéntica proporción.

- Si $0<r<1$, existe una correlación positiva.

- Si $\mathrm{r}=-1$, existe una correlación negativa perfecta. El índice indica una dependencia total entre las dos variables llamada relación inversa: cuando una de ellas aumenta, la otra disminuye en idéntica proporción.

- $\quad \mathrm{Si}-1<\mathrm{r}<0$, existe una correlación negativa.

Como se dijo con anterioridad, se considerarán como relaciones significativas desde un $90 \%$, teniendo en cuenta que lo más seguro y común en el análisis estadístico es el 95\% de confianza.

A su vez, para efectos de este estudio, calificaremos el grado de correlación de variables:

- Si r es mayor a $70 \%$ la correlación es “Alta".

- Sir es mayor a 50 \% y menor a 70\% la correlación es "Media", y

- Sir es menor a 50 \% la correlación es "Baja".

Esta graduación nos ayudará a definir la medida de correlación entre las variables, cuando los resultados obtenidos no se enmarquen dentro de los indicadores de confianza. Así, podremos hablar de la existencia de una alta correlación, que nos servirá para a lo menos, presumir una propensión o inclinación de las variables analizadas.

\subsection{Correlación de Variable Dependiente y de Control y Variable Población Penal.}

Con esta correlación, entre otras cosas, podremos confirmar o descartar la tesis del profesor Levitt que, a mayor población penal, menor es la tasa de denuncia.

\footnotetext{
${ }^{74}$ Supra: Véase Apartado 1.
} 
SALINERO, Sebastián. "Incidencia de la Probabilidad de Condena en los Delitos de Robo. Análisis Descriptivo y Comparado."

\subsubsection{En Chile.}

En la Tabla 13 podemos ver que existe una alta correlación positiva entre la tasa de reclusos y la tasa de robo con fuerza, debidamente confirmada su tendencia por la variable de control del robo con violencia. Esto, quiere decir que si aumenta la denuncia, probablemente aumenta la población penal. Los resultados para el caso de crecimiento de la población penal son altos, en razón de un $87 \%$ en el robo con fuerza y un $92 \%$ en el robo con violencia.

Como se dijo anteriormente, conforme a la correlación mostrada, no se corrobora en nuestro país la tesis disuasiva de Levitt, en orden a que si existe un aumento de la población penal, debiese existir por otro lado una disminución de la tasa de denuncia. ${ }^{75}$ El hecho que no se corrobore no significa que sea falsa: quizás en Chile la incapacitación prime sobre la disuasión y aún no se haya alcanzado el "punto de equilibrio" al respecto (porque, por ejemplo, debido a la existencia de un efecto sustitución, los criminales incapacitados estén siendo sustituidos por otros cuyos delitos son objeto sólo de denuncia).

El comportamiento elástico de ambas variables difiere de la relación inversa que debiese existir para justificar la tesis.

Tabla 13. Correlación en Chile de la Tasa del Robo con Fuerza, Robo con Violencia y Tasa de Reclusos.

\begin{tabular}{c|ccc}
\hline Año & Tasa Robo con Fuerza & Tasa Robo con Violencia & Tasa Reclusos \\
\hline 1998 & 486,4 & 98,9 & 179 \\
1999 & 576,1 & 137,7 & 198 \\
2000 & 552,0 & 166,6 & 215 \\
2001 & 686,2 & 182,0 & 216 \\
2002 & 772,6 & 190,4 & 222 \\
2003 & 872,7 & 248,0 & 228 \\
2004 & 943,8 & 289,6 & 226 \\
2005 & 974,8 & 300,8 & 228
\end{tabular}

\footnotetext{
${ }^{75}$ En general, los estudios internacionales establecen una relación entre la cantidad de Población Penal y la delincuencia. La relación que plantean estas investigaciones es negativa, es decir, un aumento en el número de encarcelamiento produce una disminución de la delincuencia, por el poder disuasivo de los encarcelamientos. Véase RUIZ/CEA/RODRÍGUEZ/MATUS, "Determinantes", cit. nota $\mathrm{n}^{\circ}$ 5, p.17. En esa misma línea, CORMAN, Hope; MOCAN, Naci, "Carrots, Sticks and Broken Windows", Journal of Law and Economics, $\begin{array}{lllll}\text { Vol. } & 48 & \text { (2005), } & \text { p. } & \text { 235-266. }\end{array}$ http://www.bus.lsu.edu/mocan/CARROTS, \%20STICKS,\%20AND\%20BROKEN\%20WINDOWS.pdf

[visitado el 25.09.2008].Una opinión contraria, entre otras, puede verse en Flacso Chile. DAMMERT, Lucia; DIAZ, Javiera, “¿Es la cárcel solución para la delincuencia?”, Observatorio Nº1, Mayo (2005). En: www.flacso.cl/getFile.php?file=file_4a8ae4ec0ad23.pdf [visitado el 25.10.2009]. La autora mediante una relación costo-beneficio sostiene que los recursos económicos utilizados en cárceles no se gastan de manera eficiente. Señala que el desarrollo para programas de tratamiento para adictos a las drogas o la prevención primaria generarían resultados mayores en el combate contra la delincuencia. En general, manifiesta la necesidad de centrar los esfuerzos para controlar la delincuencia en la prevención, control del delito y iniciativas de rehabilitación penitenciaria.
} 
Polit. crim. Vol. 4, No 8 (Diciembre 2009), Art. 5, pp. 430-474 (1-45).

[http://www.politicacriminal.cl/Vol_04/n_08/Vol4N8A5.pdf]

\begin{tabular}{c|ccc}
2006 & 960,9 & 308,7 & 240 \\
2007 & $1.018,9$ & 356,7 & 263 \\
\hline & R: $\mathbf{0 , 8 7}$ & $\mathbf{R : 0 , 9 2}$
\end{tabular}

Fuente: Elaboración propia de los datos obtenidos desde el Ministerio Público, Instituto Nacional de Estadísticas y Ministerio del Interior. En: http://www.ministeriopublico.cl/; http://www.ine.cl/ y http://www.seguridadciudadana.gov.cl/

\subsubsection{En Estados Unidos.}

Tabla 14. Correlación en Estados Unidos de la Tasa del Robo con Fuerza, Robo con Violencia y Tasa de Reclusos.

\begin{tabular}{c|ccc}
\hline Año & Tasa Robo con Fuerza & Tasa Robo con Violencia & Tasa Reclusos \\
\hline 1998 & 862,0 & 165,2 & 669 \\
1999 & 770,4 & 150,1 & 691 \\
2000 & 728,4 & 144,9 & 684 \\
2001 & 741,8 & 148,5 & 685 \\
2002 & 746,2 & 145,9 & 701 \\
2003 & 741,0 & 142,5 & 712 \\
2004 & 729,9 & 136,7 & 723 \\
2005 & 728,9 & 141,1 & 737 \\
2006 & 732,3 & 150,0 & 751 \\
\hline
\end{tabular}

Fuente: Elaboración propia de los datos obtenidos desde el Departamento de Justicia de los Estados Unidos y UCR. En http://www.ojp.usdoj.gov/y http://www.fbi.gov/

Para el caso estadounidense, la relación entre tasa de reclusos y la tasa de robo con fuerza, al igual que la variable de control, es negativa. La relación a comprobar no es significativa en el porcentaje de interés, de manera que no se puede aseverar la correlación con la confianza requerida. En todo caso, con esta relación de nivel medio, se entiende que a medida que aumenta la población penal, existe una probable disminución de la tasa de denuncia. En todo caso, estas son meras apreciaciones que no tienen un sustento empírico.

\subsubsection{En España.}

En España, existe una correlación negativa o inversa alta entre la tasa de reclusos y la tasa dependiente y de control. Esto quiere decir que, mientras aumenta la población penal disminuye, en casi la misma proporción, la denuncia. Los resultados para el caso de crecimiento de la población penal son estadísticamente confiables a un $-92 \%$ en el robo con fuerza y un $-0,93 \%$ en el robo con violencia. 
SALINERO, Sebastián. "Incidencia de la Probabilidad de Condena en los Delitos de Robo. Análisis Descriptivo y Comparado."

Tabla 15. Correlación en España de la Tasa del Robo con Fuerza, Robo con Violencia y Tasa de Reclusos.

\begin{tabular}{c|ccc}
\hline Año & Tasa Robo con Fuerza & Tasa Robo con Violencia & Tasa Reclusos \\
\hline 1998 & 567,6 & 257,5 & 112 \\
1999 & 596,7 & 250,5 & 113 \\
2000 & 554,8 & 230,8 & 112 \\
2001 & 602,1 & 254,8 & 113 \\
2002 & 572,8 & 244,7 & 121 \\
2003 & 518,6 & 209,4 & 128 \\
2004 & 474,8 & 191,7 & 136 \\
2005 & 471,6 & 188,9 & 138 \\
\hline \multicolumn{5}{c}{}
\end{tabular}

Fuente: Elaboración propia de los datos obtenidos desde el Instituto Nacional de Estadísticas de España y Ministerio del Interior de España, en http://www.ine.es/ y http://www.mir.es/

Se puede especular que los resultados obtenidos son compatibles con la tesis disuasiva del profesor Levitt, ya tantas veces mencionada, que explica que el aumento de la población penal debiese traer aparejado una disminución de las tasas de denuncia. Esta compatibilidad la debemos establecer en términos relativos de certeza y no absolutos, ya que pudiera ocurrir, por ejemplo, que viendo que la policía se centra en los robos (y es eficiente en su esclarecimiento), los delincuentes desplazarán su actividad a otros delitos. ${ }^{76}$

\subsection{Correlación de variables Suspensión de la Pena y Variable Dependiente y de Control.}

Probablemente esta correlación nos podrá informar del comportamiento de la tasa de suspendidos para la variación, sea positiva o negativa, que presente la tasa de denuncias del robo con fuerza y el robo con violencia. Esta correlación pudiese ser importante para eventualmente confirmar o descartar que a más denuncia, menos suspendidos o beneficiados por alternativas a la pena de prisión.

\footnotetext{
${ }^{76}$ Existe evidencia empírica de que la policía centra sus capacidades en ciertos y determinados delitos, o bien, en determinadas zonas y que los delincuentes desplazan su actividad criminal a otros delitos u otras zonas más vulnerables. Véase: BRAGA, Anthony, Problem-Oriented Policing and Crime Prevention, $2^{\circ}$ Ed., New York: Criminal Justice Press, 2008, p. 192 y ss.. TOWN, Stephen, "Crime Displacement. The perception, problems, evidence and supporting theory", Home Office (2001).

En: http://www.crimereduction.homeoffice.gov.uk/skills/skills10.htm [visitado el 23.03.2009]. DONOHUE, John; HO, Daniel, "Does Terrorism Increase Crime? A Cautionary Tale.", Economics and Public Policy Working Paper Series, Paper 291 (2005), pp. 1-16. En: http://sr.nellco.org/cgi/viewcontent.cgi?article=1034\&context=yale/lepp $\quad$ [visitado el 2.10.2008]. HESSELING, René B.P., "Displacement: A Review of the Empirical Literature", en Clarke (ed.): Crime Prevention Studies, vol. 3, Criminal Justice Press, Monsey, New York (1994), pp. 197-230. En: http://www.popcenter.org/library/crimeprevention/volume_03/07_hesseling.pdf [visitado el 25.03.2009].
} 
Polit. crim. Vol. 4, No 8 (Diciembre 2009), Art. 5, pp. 430-474 (1-45).

[http://www.politicacriminal.cl/Vol_04/n_08/Vol4N8A5.pdf]

\subsubsection{En Chile.}

Tabla 16. Correlación en Chile de la Tasa del Robo con Fuerza, Robo con Violencia y Tasa de Suspensión de la Pena

\begin{tabular}{c|ccc}
\hline Año & $\begin{array}{c}\text { Tasa Denuncia Robo } \\
\text { con Fuerza }\end{array}$ & $\begin{array}{c}\text { Tasa Denuncia Robo con } \\
\text { Violencia }\end{array}$ & $\begin{array}{c}\text { Tasa de } \\
\text { Suspendidos }\end{array}$ \\
\hline 1998 & 486,4 & 98,9 & 202,5 \\
1999 & 576,1 & 137,7 & 209,3 \\
2000 & 552,0 & 166,6 & 205,9 \\
2001 & 686,2 & 182,0 & 197,9 \\
2002 & 772,6 & 190,4 & 182,5 \\
2003 & 872,7 & 248,0 & 179,6 \\
2004 & 943,8 & 289,6 & 171,5 \\
2005 & 974,8 & 300,8 & 162,1 \\
2006 & 960,9 & 308,7 & 196,8 \\
2007 & $1.018,9$ & 356,7 & 264,1 \\
\hline \multicolumn{5}{c}{} & R:-0,05 & R: $\mathbf{0 , 1 0}$ &
\end{tabular}

Fuente: Elaboración propia de los datos obtenidos desde el Ministerio Público, Instituto Nacional de Estadísticas y Ministerio del Interior. En: http://www.ministeriopublico.cl/; http://www.ine.cl/ y http://www.seguridadciudadana.gov.cl/

Como se observa en la tabla de correlaciones, las eventuales relaciones entre variable dependiente y la variable de control y la tasa de suspendidos no tiene la suficiencia del indicador estadístico requerido para alcanzar la confianza a exponer en este informe. En síntesis, los resultados alcanzados, además de calificarlos de bajos y contradictorios entre sí, no permiten arribar a resultados concluyentes.

\subsubsection{En Estados Unidos.}

Con respecto al caso estadounidense, la correlación entre tasa de suspendidos (Probation) y la tasa de robo con fuerza, al igual que la variable de control, es de una relación inversa. Esto significa que, en el evento de tener la delincuencia una disminución en su tasa, las suspensiones de la pena aumentan en términos confiables. En lo que dice relación con la variable de control, ésta también alcanza el mismo resultado, el que podemos calificar de alto.

Esta correlación inversa hace probable el planteamiento que a menor tasa de denuncia es mayor la tasa de suspendidos. No obstante, para tener certeza de la afirmación hay que realizar una regresión por un período mayor. 
SALINERO, Sebastián. "Incidencia de la Probabilidad de Condena en los Delitos de Robo. Análisis Descriptivo y Comparado.”

Tabla 17. Correlación en Estados Unidos de la Tasa del Robo con Fuerza, Robo con Violencia y Tasa de Suspensión de la Pena.

\begin{tabular}{|c|c|c|c|}
\hline Año & $\begin{array}{c}\text { Tasa Denuncia Robo } \\
\text { con Fuerza }\end{array}$ & $\begin{array}{c}\text { Tasa Denuncia Robo con } \\
\text { Violencia } \\
\end{array}$ & Tasa de Suspendidos \\
\hline 1998 & 862,0 & 165,2 & 1.258 \\
\hline 1999 & 770,4 & 150,1 & 1.409 \\
\hline 2000 & 728,4 & 144,9 & 1.351 \\
\hline 2001 & 741,8 & 148,5 & 1.373 \\
\hline 2002 & 746,2 & 145,9 & 1.388 \\
\hline 2003 & 741,0 & 142,5 & 1.393 \\
\hline 2004 & 729,9 & 136,7 & 1.403 \\
\hline 2005 & 728,9 & 141,1 & 1.398 \\
\hline 2006 & 732,3 & 150,0 & 1.408 \\
\hline
\end{tabular}

R: - $\mathbf{0 , 8 0} \quad R: \mathbf{- 0 , 8 0}$

Fuente: Elaboración propia de los datos obtenidos desde el Departamento de Justicia de los Estados Unidos y UCR. En http://www.ojp.usdoj.gov/y http://www.fbi.gov/

\subsubsection{En España.}

Tabla 18. Correlación en España de la Tasa del Robo con Fuerza, Robo con Violencia y Tasa de Suspensión de la Pena.

\begin{tabular}{c|ccc}
\hline \multicolumn{1}{c}{ Año } & $\begin{array}{c}\text { Tasa Denuncia Robo con } \\
\text { Fuerza }\end{array}$ & $\begin{array}{c}\text { Tasa Denuncia Robo con } \\
\text { Violencia }\end{array}$ & Tasa de Suspendidos \\
\hline 1998 & 567,6 & 257,5 & 25 \\
1999 & 596,7 & 250,5 & 28 \\
2000 & 554,8 & 230,8 & 36 \\
2001 & 602,1 & 254,8 & 50 \\
2002 & 572,8 & 244,7 & 65 \\
2003 & 518,6 & 209,4 & 81 \\
2004 & 474,8 & 191,7 & 120 \\
2005 & 471,6 & 188,9 & 124 \\
\hline
\end{tabular}

R: $\mathbf{- 0 , 9 0}$

R: $\mathbf{- 0 , 9 1}$

Fuente: Elaboración propia con los datos obtenidos desde el Instituto Nacional de Estadísticas de España y Ministerio del Interior de España, en http://www.ine.es/ y http://www.mir.es/

Para el caso español, existe una correlación negativa alta, casi perfecta, entre la tasa de suspendidos y tasa de robo con fuerza y tasa de robo con violencia. Se prueba de manera confiable, en términos de un $90 \%$, que en la medida que disminuye la delincuencia, aumentan los favorecidos por la suspensión de la pena.

Como se dijo, a propósito del caso norteamericano, la correlación en el caso español es semejante, haciendo probable la premisa que a menor tasa de denuncia es mayor la tasa de 
Polit. crim. Vol. 4, No 8 (Diciembre 2009), Art. 5, pp. 430-474 (1-45).

[http://www.politicacriminal.cl/Vol_04/n_08/Vol4N8A5.pdf]

suspendidos. Esta afirmación también debe ser objeto de una validación empírica que considere una frecuencia mayor.

\subsection{Correlación de variable Condena y variable Dependiente y de Control.}

La correlación entre variable condena y la tasa de denuncia del robo con fuerza y robo con violencia, ayudaría eventualmente a probar o descartar, que a mayor denuncia es mayor la tasa de condena. Asimismo, las mencionadas tablas permitirán elaborar las tablas de probabilidad de condena para la variable dependiente y de control.

\subsubsection{En Chile}

Tabla 19. Correlación en Chile de la Tasa del Robo con Fuerza, Robo con Violencia y Tasa de Condena. ${ }^{77}$

\begin{tabular}{c|cccc}
\hline \multirow{2}{*}{ Año } & $\begin{array}{c}\text { Tasa Denuncia } \\
\text { Robo con Fuerza }\end{array}$ & Tasa Condena Rofu & $\begin{array}{c}\text { Tasa Denuncia Robo } \\
\text { con Violencia }\end{array}$ & Tasa Condena Rovio \\
\hline 1998 & 486,4 & 26,4 & 98,9 & 14,9 \\
1999 & 576,1 & 27,6 & 137,7 & 14,6 \\
2000 & 552,0 & 30,6 & 166,6 & 17,6 \\
2001 & 686,2 & 25,0 & 182,0 & 20,6 \\
2002 & 772,6 & 7,9 & 190,4 & 26,5 \\
2003 & 872,7 & 21,4 & 248,0 & 22,0 \\
2004 & 943,8 & 11,6 & 289,6 & 13,0 \\
2005 & 974,8 & 46,1 & 300,8 & 34,6 \\
2006 & 960,9 & 68,3 & 308,7 & 58,4 \\
\hline & \multicolumn{5}{r}{$\mathbf{r} 0,2$} & & R: $\mathbf{0 , 6}$
\end{tabular}

Fuente: Elaboración propia de los datos obtenidos desde el Ministerio Público, Instituto Nacional de Estadísticas y Ministerio del Interior. En: http://www.ministeriopublico.cl/; http://www.ine.cl/ y http://www.seguridadciudadana.gov.cl/

La relación entre la tasa de robo con fuerza y la tasa de condena del mismo delito es baja, de modo que no permite sostener ninguna conclusión en particular, salvo la probable tendencia positiva de su comportamiento.

Para el caso del robo con violencia, si bien no se alcanzan los estándares requeridos de confianza, existe una relativa relación directa entre ambas variables, pero no suficiente para ser concluyente.

\subsubsection{En Estados Unidos.}

En el caso estadounidense, los resultados obtenidos no permiten concluir o descartar un comportamiento determinado en las variables analizadas. Las evaluaciones terminadas plantean la probabilidad de negar lugar a la posibilidad de relaciones entre la tasa de denuncias del robo con fuerza y robo con violencia, con sus respectivas tasas de condenas.

\footnotetext{
${ }^{77}$ La Tabla para su elaboración sólo considera sentencias condenatorias que impusieron una pena de prisión.
} 
SALINERO, Sebastián. "Incidencia de la Probabilidad de Condena en los Delitos de Robo. Análisis Descriptivo y Comparado.”

Tabla 20. Correlación en Estados Unidos de la Tasa del Robo con Fuerza, Robo con Violencia y Tasa de Condenas. ${ }^{78}$

\begin{tabular}{l|cccc}
\hline \multicolumn{1}{c}{ Año } & Tasa Robo con & Tasa Robo con & \\
& Fuerza & Tasa Condena Rofu & Violencia & Tasa Condena Rovi \\
\hline 1998 & 862,0 & 43,2 & 165,2 & 57,2 \\
1999 & 770,4 & 44,0 & 150,1 & 59,5 \\
2000 & 728,4 & 41,1 & 144,9 & 57,1 \\
2001 & 741,8 & 38,8 & 148,5 & 55,4 \\
2002 & 746,2 & 36,1 & 145,9 & 53,5 \\
2003 & 741,0 & 41,9 & 142,5 & 56,3 \\
2004 & 729,9 & 44,4 & 136,7 & 57,8 \\
2005 & 728,9 & 46,1 & 141,1 & 59,2 \\
2006 & 732,3 & 45,1 & 150,0 & 59,4 \\
\hline
\end{tabular}

\section{R: 0,04}

R: 0,00

Fuente: Elaboración propia de los datos obtenidos desde el Departamento de Justicia de los Estados Unidos y UCR. En http://www.ojp.usdoj.gov/y http://www.fbi.gov/

\subsubsection{En España.}

Tabla 21. Correlación en España de la Tasa del Robo con Fuerza, Robo con Violencia y Tasa de Condena. ${ }^{79}$

\begin{tabular}{|c|c|c|c|c|}
\hline \multirow[b]{2}{*}{ Año } & \multirow{2}{*}{$\begin{array}{c}\text { Tasa Robo con } \\
\text { Fuerza } \\
\end{array}$} & \multicolumn{3}{|c|}{ Tasa Robo con } \\
\hline & & Tasa Condena Rofu & Violencia & Tasa Condena Rovi \\
\hline 1998 & 567,6 & 86,9 & 257,5 & 41,5 \\
\hline 1999 & 596,7 & 94,3 & 250,5 & 42,2 \\
\hline 2000 & 554,8 & 66,5 & 230,8 & 48,9 \\
\hline 2001 & 602,1 & 69,2 & 254,8 & 54,5 \\
\hline 2002 & 572,8 & 69,8 & 244,7 & 57,6 \\
\hline 2003 & 518,6 & 62,8 & 209,4 & 51,0 \\
\hline 2004 & 474,8 & 57,9 & 191,7 & 47,3 \\
\hline 2005 & 471,6 & 59,5 & 188,9 & 45,9 \\
\hline
\end{tabular}

R: 0,7

R: 0,1

Fuente: Elaboración propia con los datos obtenidos desde el Instituto Nacional de Estadísticas de España y Ministerio del Interior de España, en http://www.ine.es/ y http://www.mir.es/

En la tabla de correlaciones se puede advertir, que para el caso de la correlación entre robo con fuerza y la condena del mismo delito, hay una relación positiva o directa, pero sin alcanzar los estándares requeridos de confianza. Podría especular que, cuando la denuncia disminuye, la condena tiene el mismo comportamiento. Para el caso de la variable de control no se obtienen resultados estadísticos significativos que permitan sostener resultados confiables.

\footnotetext{
${ }^{78}$ La Tabla para su elaboración sólo considera sentencias condenatorias que impusieron una pena de prisión.

${ }^{79}$ La Tabla para su elaboración sólo considera sentencias condenatorias que impusieron una pena de prisión.
} 


\section{Polít. crim. Vol. 4, № 8 (Diciembre 2009), Art. 5, pp. 430-474 (1-45). [http://www.politicacriminal.cl/Vol_04/n_08/Vol4N8A5.pdf]}

Conforme a la graduación de los indicadores, si bien el resultado obtenido para el delito de robo con fuerza es alto, éste no se pudo confirmar en el delito de robo con violencia.

\section{Probabilidad de Condena.}

La Teoría de la Disuasión (Deterrence), retomada con fuerza por Gary Becker, siendo una de sus aportaciones a la teoría económica que le valiera el Premio Nóbel de Economía, cuyo primer esbozo le corresponde a Beccaria $^{80}$ (1764) y luego a Bentham ${ }^{81}$ (1789), se ha convertido en una de las áreas más desarrolladas del Análisis Económico del Derecho Law \& Economics- ${ }^{82}$ Este autor diseñó una ecuación para medir el beneficio neto obtenido por un delincuente al cometer un crimen. Aquella, demuestra que aumentar la probabilidad de ser arrestado, la probabilidad de ser sentenciado, la dureza de las penas y otros asociados a creencias religiosas o éticas, disminuye en forma directa el beneficio esperado neto de delinquir, y por lo tanto, el número de gente dispuesta a cometer un delito. Este modelo, desde su aparición, cuenta con innumerables estudios empíricos, entre otros, los de Ehrlich, ${ }^{83}$ Blumstein y Nagin, ${ }^{84}$ y Wolpin. ${ }^{85}$

${ }^{80}$ BECCARIA, Cesare, Tratado de los Delitos y de las Penas, México: Edit Porrúa, 15 Edición, 2005, p.31: "El fin, pues, no es otro que impedir al reo causar nuevos daños a sus ciudadanos, y retraer a los demás de la comisión de otros iguales." Un aporte interesante de Beccaria es la propuesta de una ecuación para determinar en qué momento una pena deja de cumplir su función. Él dice: "que el valor esperado del delito es igual al "bien" perseguido por el delincuente, multiplicado por la probabilidad de que dicho "bien" se obtenga (o, lo que es lo mismo, el valor absoluto del "bien" perseguido menos la probabilidad de no obtenerse). Luego, debe tomarse el "mal" de la pena prevista y multiplicarse por la probabilidad de que la pena resulte impuesta (la infalibilidad de la pena). Si el valor resultante es mayor al primero, entonces la pena prevista consigue su objeto".

${ }^{81}$ BENTHAM, Jeremy, Compendio de los Tratados de Legislación Civil y Penal. Madrid: Librería de la Viuda de Callejas e Hijos, 1839. Para el autor, es indispensable que quien cometa un delito deba ser sancionado indefectiblemente para que, de esa manera, en la mente del posible infractor, exista o se cree la probabilidad segura de una sanción y debido a que el delincuente es racional, él "calcularía" el riesgo de ser o no detenido por alcanzar su objetivo delictivo, pero este aspecto depende de la adecuada prescripción de la ley.

${ }^{82}$ El propio Becker reconoce que, su modelo no es otra cosa que una modernización en términos matemáticos y econométricos, de los planteamientos de Beccaria, de quien es la afirmación de que "no es la dureza de las penas uno de los más grandes frenos de los delitos, sino la infalibilidad de ellas", por una parte; y, por la otra, de Bentham, para quien "el valor de la pena no debe ser menor en ningún caso que el que es suficiente para compensar el beneficio del delito". En: MATUS RAMIREZ, Jean Pierre, "El Ministerio Público y una Política Criminal en una Sociedad Democrática.", Revista de Derecho, Vol. XIX- No 2, Diciembre (2006), pp. 187-203, p. 194.

3 EHRLICH, Isaac, "Participation in Illegitimate Activities: A Theoretical and Empirical Investigation", Journal of Political Economy, vol.81 (1973), p. 521-565. Cit: COOTER, Robert; ULEN, Thomas, Derecho y Economía, Trad. SUAREZ, Eduardo, México: Edit. Fce (2002), p.586. Utilizó datos sobre los robos en todo los Estados Unidos en 1940, 1950, y 1960, para estimar la hipótesis de la disuasión y concluyó que, entre mayor sea la probabilidad de condena por el robo, menor será la tasa de robos. Ehrlich descubrió también que no había ningún efecto de disuasión imputable a la severidad del castigo, medida por la duración media de una sentencia de prisión por robo en los años 1940 y 1960, pero que sí había tal efecto en 1950.

${ }^{84}$ BLUMSTEIN, Alfred; NAGIN, Daniel, "The Deterrent Effect of Legal Sanctions on Draft Evasion", Standford Law Review, Vol. 28 (1977), p. 241. Cit: COOTER/ULEN, Derecho, cit. nota $\mathrm{n}^{\circ}$ 83, p. 586, Blumstein y Nagin estudiaron la relación existente entre la evasión de la conscripción y su castigo en los años sesenta y setenta. Estos autores concluyeron que, una probabilidad mayor de la condena y nivel mayor de la pena tendían a causar una tasa menor de evasión de la conscripción. 
SALINERO, Sebastián. "Incidencia de la Probabilidad de Condena en los Delitos de Robo. Análisis Descriptivo y Comparado."

Becker propone que los delincuentes no razonan de manera diferente al resto de las personas, ya que analizan su comportamiento en función de las oportunidades potenciales a que se enfrentan, y que esto lo realizan a través de un razonamiento de ganancias pérdidas. Con esto, no se plantea que los infractores de ley realicen un cálculo estadístico para determinar su acción, sino que dentro de las variables que llevan a una persona a cometer este tipo de actos, existe una que se acentúa en gran medida en ilícitos de carácter económico, la que dice relación con que estas personas actúan a partir de las ganancias y de los bajos costos potenciales que observan en estos actos, a diferencia de otras actividades consideradas legales. De esta manera, la teoría analiza el comportamiento delictivo como una respuesta a las oportunidades que enfrentan los potenciales delincuentes, a los que, insertos en un contexto específico de un alto aprendizaje delictivo, de necesidades y carencias económicas, contextos sociales de riesgo y donde se observa una gran impunidad, se les presenta como atractiva la opción de incurrir en actos delictuales, por las utilidades que ven en ellos. Así, se plantea que a partir de los altos beneficios económicos extraídos de un delito y de los posibles costos dados, principalmente, por la probabilidad de ser arrestado, la probabilidad de ser sentenciado, la dureza de las penas y otros asociados a creencias religiosas o éticas, se realiza un sopesamiento de dichas variables y se llega a la decisión de, o bien realizar el acto delictivo, o bien recurrir a otros métodos de ganancias económicas. $^{86}$

La pena es un real coste para el delincuente, la cual tiene un poder disuasivo, que se ha medido: con la severidad de la pena, que se refiere tanto a la duración de la sentencia en el

\footnotetext{
${ }^{85}$ WOLPIN, Kenneth, "An Economic Analysis of Crime and Punishment in England and Wales 1894-1967", Journal of Political Economy, vol. 86 (1978), p. 815. Cit: COOTER/ULEN, Derecho, cit. nota n ${ }^{\circ}$ 83, p. 587. Wolpin utilizó datos de series de tiempo de Inglaterra y Gales, durante el período de 1894-1967, para verificar un efecto de disuasión en esos países. Wolpin descubrió que las tasas delictivas del Reino Unido constituían una función inversa de la probabilidad y la severidad del castigo.

${ }^{86}$ Una crítica al modelo de disuasión puede verse en: GARCIA-PABLOS DE MOLINA, Antonio, Tratado de Criminología, cit. nota $\mathrm{n}^{\mathrm{o}} 21$, p. 995 . "Una sustancial mejora de la efectividad del sistema legal incrementa, desde luego, el volumen del crimen registrado, se captura más crimen y reduce la desproporción entre los valores "oficiales" y los "reales" (cifra negra). Pero no por ello se evita más crimen ni se produce o genera menos delito en idéntica proporción; se detecta más crimen. Mala política criminal aquella que contempla el problema social del delito en términos de mera "disuasión", desentendiéndose del imprescindible análisis etiológico de aquél y de genuinos programas de prevención (prevención primaria).". En la misma línea: GARCIA-PABLOS DE MOLINA, Antonio, Introducción al Derecho Penal, Madrid: Ed. Universitaria, 2005, p. 337. Otra crítica en KURY, Helmut, Sobre la relación entre sanciones y criminalidad, o: ¿Qué efecto preventivo tienen las penas?, Trad.: HERNANDEZ PLASENCIA, José. En: Modernas tendencias en la ciencia del derecho penal y en la criminología, Madrid: Universidad Nacional de Educación a Distancia, 2001, p. 304: "Consideramos la evolución de la criminalidad en Alemania en comparación con la cuota de encarcelamiento durante las últimas décadas, llegando a un resultado comparable: de nuevo se nos permite mostrar de la mejor manera ninguna influencia - al menos ninguna consistente - de la cuota se encarcelamiento sobre la tasa de delitos de un país, es decir, que en gran parte sea resultado de las penas más severas impuestas, a saber la pena privativa de libertad.... La impresión es clara: que en la Republica Federal de Alemania, o bien en Alemania unificada después del cambio, se desarrolló la tasa de criminalidad (considerablemente), sin estar influida por la cifra de encarcelamiento, esto es, por la práctica sancionatoria de los tribunales, especialmente en la dimensión de las penas privativas de libertad impuestas.". La afirmación de Kury es apresurada, no podemos decir que la cárcel no disuada simplemente al observar un crecimiento paralelo entre la tasa de denuncia y la población penal. Este fenómeno puede deberse a múltiples factores criminógenos que pueden explicar la situación y que ya esgrimiremos.
} 
Polit. crim. Vol. 4, No 8 (Diciembre 2009), Art. 5, pp. 430-474 (1-45).

[http://www.politicacriminal.cl/Vol_04/n_08/Vol4N8A5.pdf]

sistema penal, generalmente, a prisión, como también a la cantidad de acciones que son consideradas delitos y que, por lo tanto, se les debe aplicar un castigo. También es medido con la certeza de que el castigo ocurra, es decir, su probabilidad de ocurrencia. Se espera que cualquiera de las dos posibilidades tenga una relación negativa con el delito. En otras palabras, que cuando aumenta la severidad y/o probabilidad de las penas, el delito disminuya.$^{87}$

Estudios llevados a cabo por autores muy diferentes e independientes entre sí, autores que han recurrido a un amplio abanico de metodologías y fuentes de información empírica distintas, sugieren en efecto, que las penas son efectivas en la prevención general del delito. Algunos atribuyen un efecto moderado y sobre todo, difícil de deslindar con nitidez de otras funciones preventivas, como la prevención que ejerce la policía, el riesgo de detención, el riesgo de condena o la inocuización, por ejemplo. ${ }^{88}$ De este modo es más prudente afirmar que la labor preventiva conjunta de las penas y la Administración de Justicia parecen ser efectivas en la prevención del delito; aquí muchos autores se muestran más optimistas sobre la magnitud del efecto, afirmando Nagin que ejerce un efecto de prevención muy sustancial. ${ }^{89}$

Por razones de tiempo y estructura del trabajo sólo estudiare la probabilidad de condena, lo que no quiere decir que la probabilidad de ser arrestado y la dureza de las penas sean menos importantes. Ambas variables requieren ser objeto de una investigación posterior, a fin de establecer empírica e íntegramente en Chile, la teoría de la disuasión.

Como he venido realizando con anterioridad, revisare la situación nacional y comparada de la probabilidad que existe de que un sujeto sea condenado. Para tales efectos, utilizare el delito de robo con fuerza y el delito de robo con violencia. Las razones para la utilización de estos tipos penales ya las esbocé con anterioridad, pero además es necesario explicar que se trata de delitos disímiles entre sí, no obstante tener un origen común. Esto permitirá tener un espectro general de la situación, toda vez que el robo con violencia atenta contra la integridad de las personas y el robo con fuerza al patrimonio. Lo ideal sería calcular la probabilidad de condena en todos los delitos, pero esto escapa a los fines de este trabajo, que tiene por objeto realizar un somero análisis que pudiese servir o sentar las bases para una investigación más lata sobre el tema.

\footnotetext{
${ }^{87}$ RUIZ/CEA/RODRÍGUEZ/ MATUS, “Determinantes", cit. nota n ${ }^{\circ}$ 5, p. 18; Otros estudios chilenos, entre otros, sobre la probabilidad de la condena, puede verse en: Libertad y Desarrollo, En: http://www.lyd.com/lyd/centro doc/documents/tp303que $\% 20$ ha $\% 20$ pasado $\% 20$ con $\% 201$ las $\% 20$ sanciones $\% 20$ penales-06-09-1996.pdf [visitado el 12.11.2009]; En Centro de Estudios de Opinión Ciudadana, http://www.ceoc.cl/docs/publicaciones_historial/Publicaciones_2008/Estudios_eco_reg/EstEcoReg-

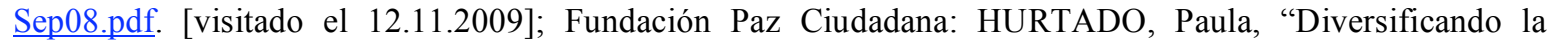
respuesta frente al delito: Procedimientos y penas alternativas" (2005), pp. 179-198. En: http:/www.pazciudadana.cl/docs/pub_20090707161146.pdf [visitado el 12.11.2009]; LAVIN, Claudio, "Toma de decisiones y control social del delito". En: http://www.cejamericas.org/doc/documentos/tomadesiciones_delito.pdf [visitado el 12.11.2009];

${ }^{88}$ Véase: BLUMSTEIN, Alfred; COHEN, John; NAGIN, Daniel, Deterrence and Incapacitation-Estimating The Effect of Criminal Sanctions on Crime Rates, United States, National Academy of Sciences, 1978, pp. 5 y ss.

${ }^{89}$ SERRANO, Criminología, cit. nota $\mathrm{n}^{\mathrm{o}} 13$, p. 272.
} 
SALINERO, Sebastián. "Incidencia de la Probabilidad de Condena en los Delitos de Robo. Análisis Descriptivo y Comparado."

La probabilidad de condena se calculará como el cuociente entre tasa de condena del delito específico en un tiempo $t$ y la tasa de denuncia para el mismo delito en un tiempo $t-1 .^{90}$

Además, aclaro que los resultados logrados deben ser vistos como una mera orientación en razón de una serie incuantificable de variables que pueden incidir en los resultados. ${ }^{91}$

\subsection{En Chile.}

Conforme la Tabla 22, referida a la evolución que ha tenido en Chile la probabilidad que un delincuente sea condenado, si bien vislumbra notables mejoras en el último año informado, en los años previos los índices son bajos. Quizás, ésta sea una de las probables razones de las altas tasas de denuncia para esos años.

Tabla 22. Evolución en Chile de la Probabilidad Condena en los Delitos de Robo con Fuerza y Robo con Violencia entre 1998-2006.

\begin{tabular}{c|cc}
\hline Año & Robo con Fuerza & Robo con Violencia \\
\hline 1998 & 0,05 & 0,14 \\
1999 & 0,04 & 0,1 \\
2000 & 0,05 & 0,1 \\
2001 & 0,03 & 0,11 \\
2002 & 0,01 & 0,13 \\
2003 & 0,02 & 0,08 \\
2004 & 0,01 & 0,04 \\
2005 & 0,04 & 0,11 \\
2006 & 0,07 & 0,18 \\
\hline
\end{tabular}

Fuente: Elaboración propia de los datos obtenidos desde el Ministerio Público, Instituto Nacional de Estadísticas y Ministerio del Interior. En: http://www.ministeriopublico.cl/; http://www.ine.cl/ y $\underline{\text { http://www.seguridadciudadana.gov.cl/ }}$

En efecto, en el periodo 1998-2006 las cifras son desalentadoras en lo que respecta al robo con fuerza, el indicador porcentual no supera en promedio el 3,5\%, lo que comunica que la probabilidad de que un delincuente sea condenado por este ilícito no supera ese tanto por ciento. Para el caso del delito de robo con violencia los datos son más animadores, por cuanto estamos recuperando los índices existentes a fines de los noventa, pero con un bajo promedio del período ascendente a un $11 \%$. Eventualmente, se podría explicar, a priori, que la alta tasa de denuncias existente en el período 2003-2004 se puede relacionar con la baja en el índice de probabilidad de condena para el mismo período.

\footnotetext{
${ }^{90}$ La misma ecuación se utiliza para calcular la probabilidad de captura en: RUIZ/CEA/RODRÍGUEZ/ MATUS, "Determinantes", cit. nota $\mathrm{n}^{\circ}$ 5, p. 15.

${ }^{91}$ Las variables que pueden incidir o que no se consideran son, a manera solamente ejemplar, la capacidad de gestión de denuncias del sistema de justicia criminal, gestión de la judicatura, etc.
} 
Polit. crim. Vol. 4, No 8 (Diciembre 2009), Art. 5, pp. 430-474 (1-45).

[http://www.politicacriminal.cl/Vol_04/n_08/Vol4N8A5.pdf]

\subsection{En Estados Unidos.}

Los datos estadounidenses permiten medir la evolución del índice de probabilidad de condena en el período 1998-2006 en el cual, para el delito de robo con fuerza, la probabilidad tiene un promedio de un $5 \%$, y el robo con violencia una probabilidad promedio de un $38 \%$, que podría explicar la caída de los delitos violentos.

De la lectura de la tabla, se puede advertir el nivel uniforme que han tenido los índices en el intervalo expuesto. Lo que pudiese explicar también, el sostenido descenso de la tasa de denuncia. Además, se podría inferir que, no sólo son importante los bajos índices, sino también, la permanencia constante de ellos en el tiempo.

Tabla 23. Evolución en Estados Unidos de la Probabilidad Condena en los Delitos de Robo con Fuerza y Robo con Violencia en el período 1998-2006.

\begin{tabular}{c|cc}
\hline Año & Robo con Fuerza & Robo con Violencia \\
\hline 1998 & 0,05 & 0,34 \\
1999 & 0,05 & 0,39 \\
2000 & 0,05 & 0,39 \\
2001 & 0,05 & 0,37 \\
2002 & 0,04 & 0,36 \\
2003 & 0,05 & 0,39 \\
2004 & 0,06 & 0,42 \\
2005 & 0,06 & 0,41 \\
2006 & 0,06 & 0,39 \\
\hline
\end{tabular}

Fuente: Elaboración propia de los datos obtenidos desde el Departamento de Justicia de los Estados Unidos y UCR. En http://www.ojp.usdoj.gov/y http://www.fbi.gov/

\subsection{En España.}

Tabla 24. Evolución en España de la Probabilidad Condena en los Delitos de Robo con Fuerza y Robo con Violencia entre los años 1998-2005.

\begin{tabular}{c|cc}
\hline Año & Robo con Fuerza & Robo con Violencia \\
\hline 1998 & 0,15 & 0,16 \\
1999 & 0,15 & 0,16 \\
2000 & 0,11 & 0,21 \\
2001 & 0,11 & 0,21 \\
2002 & 0,12 & 0,23 \\
2003 & 0,12 & 0,24 \\
2004 & 0,12 & 0,24 \\
2005 & 0,13 & 0,24 \\
\hline
\end{tabular}

Fuente: Elaboración propia con los datos obtenidos desde el Instituto Nacional de Estadísticas de España y Ministerio del Interior de España, en http://www.ine.es/ y http://www.mir.es/ 
SALINERO, Sebastián. "Incidencia de la Probabilidad de Condena en los Delitos de Robo. Análisis Descriptivo y Comparado."

En España, contamos con importante información que permitirá especular que en lo relativo al robo con fuerza, en el período investigado, exista un índice de probabilidad de condena de un 13\% promedio para el robo con fuerza. Asimismo, la baja exposición de los delitos violentos pudiese deberse a la alta probabilidad de condena que refleja el índice del robo con violencia en los últimos años investigados, el cual muestra un porcentaje promedio en el orden del $22 \%$. Esto implica que, en lo que respecta al robo con violencia, que dicho sea de paso es el delito violento más usual en España, ${ }^{92}$ una de cada cuatro denuncias por este delito termina con una persona condenada.

\section{Conclusiones.}

\section{1}

En cuanto a la hipótesis de si la población penal incide en el aumento o disminución de la tasa de denuncia de los delitos de robo, la estadística analizada muestra que en España y en Estados Unidos el aumento de la población penal, aparentemente, trae aparejada una disminución de la tasa de denuncia del delito de robo. Tratándose del primer comparado, la premisa se confirmó en un $90 \%$ de confianza. Respecto del caso Norteamericano, la premisa no se confirma con los niveles satisfactorios requeridos, pero es probable, que tenga la misma tendencia. ${ }^{93}$

Para el caso chileno, el aumento de la población penal no trae como consecuencia una disminución de la tasa de denuncia del delito de robo. Ambas variables se comportan de manera positiva, una con un $87 \%$ (robo con fuerza) y la otra con un $92 \%$ (robo con violencia), de modo tal que, si aumenta una, aumenta la otra, en prácticamente la misma proporción. Este comportamiento no es auspicioso y, de una lectura especulativa, puedo sostener dos posibles hipótesis: que la cárcel no disuade en los términos esperados y pregonados por el profesor Levitt, o a lo mejor, se reafirma la tesis en el sentido de sostener que si no existiesen los niveles actuales de encarcelamiento la tasa de denuncia sería incluso mayor. Como se dijo anteriormente, una hipótesis es, quizás en Chile, que la incapacitación prime sobre la disuasión y aún no se haya alcanzado el "punto de equilibrio" al respecto.

Estimo que pudiese ser correcto para devolver el carácter disuasivo de la cárcel, que existiese un tránsito dinámico entre ingreso y egresos a la prisión, dado que aparentemente los centros de reclusión están colapsados con condenados que cumplen penas de cuantías elevadísimas para una serie importantes de delitos que en la experiencia comparada se les asigna una pena significativamente menor. Lo más probable es que esta disuasión se lograría con penas de corta duración, las cuales, dicho sea de paso, corresponderían a principio de proporcionalidad. Así por ejemplo, si aplicamos penas de corta duración a delitos como el robo con fuerza, que hoy tiene asignada una pena excesiva, esto nos permitirá, encarcelar a más gente, dar cumplimiento a los fines de la pena y ahorrar

\footnotetext{
92 Según el Ministerio del Interior de España, Gabinete de Estudios de Seguridad Interior. Véase Balance de Criminalidad en España año 2005 y 2006. En: http://www.mir.es/

93 En el caso de Finlandia, según elaboración propia, para el período 2000-2006, se confirma la premisa con un $70 \%$.
} 
Polit. crim. Vol. 4, No 8 (Diciembre 2009), Art. 5, pp. 430-474 (1-45).

[http://www.politicacriminal.cl/Vol_04/n_08/Vol4N8A5.pdf]

importantes recursos económicos para ser destinados a la persecución y juzgamiento de otros delincuentes.

\section{2.}

Tratándose de la hipótesis de si la suspensión de la pena produce algún efecto en la tasa de denuncia de los delitos de robo, la estadística revisada muestra que en Estados Unidos y España existe una relación inversa que se podría explicar que en la medida que disminuye la denuncia de los delitos de robo en ambos países, aumenta la suspensión de la pena en casi la misma proporción. Estas relaciones se verificaron en términos altos por sobre el $80 \%$, lo que permite describir el comportamiento de la correlación en términos negativos.

En el caso chileno, la correlación con la tasa de suspendidos no tiene la suficiencia del indicador estadístico requerido para alcanzar la confianza a exponer en este informe. Se obtiene por una parte una correlación negativa del $5 \%$ para el robo con fuerza y positiva de un $10 \%$ para el robo con violencia.

Por otra parte, se podría pensar que una reducción en Chile de la tasa de suspendidos o beneficiados por la Ley $\mathrm{N}^{\mathrm{o}} 18.216$, devolvería bajas tasas para los delitos de robo. Hoy se escucha en los medios de comunicación cómo la clase política exige la aplicación irrestricta de la prisión, por sobre una eventual suspensión de la pena. ${ }^{94}$ Es dable refutar a los diversos sectores en orden a señalar que esta premisa no es corroborada empíricamente. Como se dijo, en los Estados Unidos desde el año 1991 hasta estos días, la tasa de denuncia presenta un descenso constante y desde los años ochenta hasta el presente tiempo, la tasa de suspendidos ha aumentado constantemente. Mostrado este escenario, estoy en condiciones de establecer plausiblemente que, la suspensión de la pena no incidió y no incide para que los Estados Unidos tengan bajas tasas de denuncia para esta especie de delitos. Asimismo, en Chile, entre los años 2000-2005, existió una baja concesión de los beneficios de la Ley $\mathrm{N}^{\circ} 18.216$, el más bajo del estudio realizado pero, por otro lado, existió las más alta tasa de denuncias y detenciones de los DMCS.

En definitiva, existe evidencia empírica para argumentar con cautela, que la eventual reducción en la utilización de la suspensión de la pena efectiva, no incide en una eventual variación negativa de la denuncia. ${ }^{95}$

\footnotetext{
${ }^{94}$ El Senador Alberto Espina ha sido un crítico del gobierno en materia de seguridad pública. Véase diario El Mercurio de fecha 23 de Noviembre del 2008.

${ }^{95}$ Cfr. con MATUS, "Por qué no", cit. nota ${ }^{\circ}$ 65, p. 85 y ss.: "Por otra parte, entre nosotros la aplicación de las medidas alternativas (remisión condicional, reclusión nocturna y libertad vigilada) de la Ley $\mathrm{N}^{\mathrm{o}} 18.216$, disponible para prácticamente todo condenado a menos de cinco años de reclusión que sea primerizo (Matus, 2003), no sólo tiene una mayor probabilidad de ocurrencia que la reclusión definitiva (aunque los términos de la relación se han ido disminuyendo, pasando de un 73,5\% en 1997 a un 59,3\% en 2004), sino que además deja un potencial de encarcelamiento que casi iguala a las tasas efectivas y que tal vez podría explicar el por qué del aparentemente nulo efecto en Chile del encarcelamiento en las tasas de criminalidad."
} 
SALINERO, Sebastián. "Incidencia de la Probabilidad de Condena en los Delitos de Robo. Análisis Descriptivo y Comparado."

\section{3.}

En la correlación entre la variable dependiente y de control versus condenas, en Estados Unidos, España y Chile, no se consiguen resultados confiables en sus indicadores, siendo las variables dispares en su graduación (alta, media y baja).

\section{4 .}

En lo que respecta a la hipótesis de si la probabilidad de condena incide en la denuncia del delito de robo, se pudo establecer que en Chile se condena 3,5 denuncias de cada 100 para el robo con fuerza y 11 denuncias del mismo índice para el robo con violencia, quizás estos bajo porcentaje sean una de las tantas causas posibles del aumento de la tasa de denuncia. Los números de los primeros años reseñados son desalentadores y entregan buenas razones para argumentar esta hipótesis. El último año testeado muestra un índice más elevado, pero no suficiente para alcanzar los fines de seguridad deseados. El caso de España permite poder explicar una de las posibles causas de las bajas tasas de denuncia, en donde, de cada 100 robos con fuerza se castiga un promedio de 13 denuncias, y para el caso de los robos con violencia se castiga 22 en promedio. Por otro lado, Estados Unidos muestra índices diferentes para el delito robo con fuerza y robo con violencia. Tratándose del primero, se puede decir que, de cada 100 denuncias de robo se castiga a 5, y respecto del más grave, que pudiese justificar la caída de los delitos violentos, se castiga un total de 38 denuncias.

De acuerdo a los datos expuestos en Chile, el delito se convierte en una actividad de poco riesgo y sin duda muy rentable. La impunidad puede ser la principal y mayor invitación a la delincuencia, en tales circunstancias, aceptando que ésta sea una de las tantas causas probables del delito.

Para aumentar el costo de las acciones delictivas, tenemos que seguir las buenas enseñanzas de la experiencia comparada como, por ejemplo, aumentar la dotación de policías, que es factor probado de disuasión (En el año 1994 el número de policías alcanzaba una tasa de 201,64, pero en los años siguientes presenta un descenso sostenido que contagia los primeros años del nuevo siglo, hasta que en el año 2005 empieza un crecimiento, terminando el año 2008 con una tasa de 243,15). Otro buen predicamento para aumentar la probabilidad de condena sería aumentar la eficacia de las policías, entendido como un aumento en las detenciones y nuevas tácticas policiales. Todo ello, podría aportar valiosos antecedentes para una mejor pesquisa del delito y sus autores. Si bien, estrategias como el Plan Cuadrante nacido en 1998 o la creación de oficinas especializadas para combatir ciertos y determinados delitos son avances importantes en esta tarea, no son suficientes, por el momento, para alcanzar los objetivos propuestos.

\section{5 .}

Otra reflexión, no menor, que se puede extraer de este estudio, es el hecho que las fuentes de información que se disponen para poder medir el delito son escasas e insuficientes. Cada organismo, sea el Ministerio del Interior o el persecutor penal u otros órganos fiscales, manejan y controlan información propia que no puede ser controlada verticalmente y 
Polit. crim. Vol. 4, No 8 (Diciembre 2009), Art. 5, pp. 430-474 (1-45).

[http://www.politicacriminal.cl/Vol_04/n_08/Vol4N8A5.pdf]

responden a intereses de gestión. Por ello es necesario, unificar criterios de información y registro, siendo lo más recomendable seguir la experiencia comparada, en especial, la derivada de organismos ingleses y estadounidenses, lo cual, no sólo nos permitirá mejorar las fuentes para poder diseñar una adecuada política criminal, sino que nos permitirá compararnos con dichos países, evaluar resultados obtenidos y poder implementar o descartar acciones ya utilizadas para combatir el delito.

\section{BIBLIOGRAFÍA}

ARAYA MOYA, Jorge; SIERRA CISTERNAS, David, "Influencia de factores de riesgo social en el origen de conductas delincuenciales. Índice de vulnerabilidad socialdelictual". Serie de estudios, División de Seguridad Pública, Ministerio del Interior, Gobierno de Chile, Junio (2002), pp. 3-82.

BECCARIA, Cesare, Tratado de los Delitos y de las Penas, México: Edit Porrúa, 15 Edición, 2005, p.31.

BECKER, Gary, "Crime and Punishment: An Economic Approach", Journal of Political Economy 76 n $^{\circ} 2$ (1968), pp. 169-217.

BENTHAM, Jeremy, Compendio de los Tratados de Legislación Civil y Penal. Madrid: Librería de la Viuda de Callejas e Hijos, 1839.

BLUMSTEIN, Alfred; COHEN, John; NAGIN, Daniel, Deterrence and IncapacitationEstimating The Effect of Criminal Sanctions on Crime Rates, United States, National Academy of Sciences, 1978, pp. 5 y ss.

BLUMSTEIN, Alfred; NAGIN, Daniel, "The Deterrent Effect of Legal Sanctions on Draft Evasion", Standford Law Review, Vol. 28 (1977), p. 241.

BRAGA, Anthony, Problem-Oriented Policing and Crime Prevention, $2^{\circ}$ Ed., New York: Criminal Justice Press, 2008, p. 192 y ss.

CASTIÑEIRA, María Teresa; RAGUÉS, Ramón, "Three Strikes. El principio de proporcionalidad en la jurisprudencia del Tribunal Supremo de los Estados Unidos", RDPCrim., $2^{\mathrm{a}}$ época, $\mathrm{n}^{\mathrm{o}} 14$ (2004), pp. 59-85.

CHAZARRA QUINTO, Maria Asunción, "La Reincidencia en el Código Penal Español: Una mirada al controvertido modelo norteamericano", Revista electrónica Derecho Penal On Line, Septiembre (2007), en: http://www.derechopenalonline.com/derecho.php?id=13,427,0,0,1,0 [visitado el 20.03.2009].

CID MOLINE, José, “El incremento de la población reclusa en España entre 1996-20006. Diagnostico y Remedio". Revista Española de Investigación Criminológica, Artículo 2, No 6 (2008), pp. 1-31.

CID MOLINE, José, "La suspensión de la pena en España: descarcelación y reincidencia", Revista de derecho penal y criminología, (2005), pp. 230-231.

COOTER, Robert; ULEN, Thomas, Derecho y Economía, Trad. SUAREZ, Eduardo, México: Edit. Fce (2002), p.586.

CORMAN, Hope; MOCAN, Naci, "Carrots, Sticks and Broken Windows", Journal of Law and Economics, Vol. 48 (2005), p. 235-266.

DAMMERT, Lucia; DIAZ, Javiera, “¿Es la cárcel solución para la delincuencia?”, Observatorio $\mathrm{N}^{\mathrm{o}} 1$, Mayo (2005). 
SALINERO, Sebastián. "Incidencia de la Probabilidad de Condena en los Delitos de Robo. Análisis Descriptivo y Comparado."

DIEZ RIPOLLES, José Luis, "La evolución del sistema de penas en España: 1975-2003." RECPC., 08-07 (2006), pp. 1-25, p. 19.

DILULIO, John; PIEHL, Ann, "Does Prison Pay? The Stormy National Debate Over the Cost-Effectiveness of Imprisonment", Brookings Review, (1991), 28-35.

DONOHUE, John, "Fighting Crime: An Economist's View", The Milken Institute Review, $7 \mathrm{n}^{\mathrm{o}} 46$ (2005), pp. $46-58$.

DONOHUE, John; HO, Daniel, "Does Terrorism Increase Crime? A Cautionary Tale.", Economics and Public Policy Working Paper Series, Paper 291 (2005), pp. 1-16.

EHRLICH, Isaac, "Participation in Illegitimate Activities: A Theoretical and Empirical Investigation", Journal of Political Economy, vol.81 (1973), p. 521-565.

FREY VALDES, Antonio, "Población Penal y Mercado Laboral: Un Modelo Empírico para el período 1982-2002 en la Región Metropolitana”. Manuscrito facilitado por su autor.

FUKUYAMA, Francis, La Gran Ruptura, La Naturaleza Humana y la Reconstrucción del Orden Social, Trad. PLACKING DE SALCEDO, Dorotea, Buenos Aires: Edit. Atlántida, 1999, p.59.

GARCIA ARAN, Mercedes, Delincuencia, inseguridad y pena en el discurso mediático. En: MUÑOZ CONDE, Francisco (Dir.), Problemas Actuales del derecho Penal y de la Criminología. Estudios penales en memoria de la Profesora Dra. María del Mar Díaz Pita, Valencia: Tirant Lo Blanch, 2008, p. 95.

GARCIA-PABLOS DE MOLINA, Antonio, Introducción al Derecho Penal, Madrid: Ed. Universitaria, 2005, p. 337.

Tirant Lo Blanch, 2003, p. 264.

, Tratado de Criminología, $3^{\circ}$ Ed., Valencia:

GARRIDO, Vicente; STANGELAND, Per; REDONDO, Santiago, Principios de Criminología, $3^{\circ}$ Ed., Valencia: Tirant Lo Blanch, 2006.

GONZALEZ BERENDIQUE, Marco, Criminología, tomo I, Santiago: Ed. Jurídica, 2004, p. 91.

HARRISON, Paige; BECK, Allen, "Prison and Jail Inmates at Midyear 2004", Bureau of Justice Statistics, U.S. Department of Justice, April (2005).

HASSEMER, Winfried; MUÑOZ CONDE, Francisco, Introducción a la Criminología. Valencia: Edit. Tirant Lo Blanch, 2001, p.288.

HERRERO HERRERO, Cesar, Criminología. Parte General y Especial, Madrid: Dykinson, 2007, p. 267.

HESSELING, René B.P., "Displacement: A Review of the Empirical Literature”, en Clarke (ed.): Crime Prevention Studies, vol. 3, Criminal Justice Press, Monsey, New York (1994), pp. 197-230.

HOFER, María Eugenia, “Medidas alternativas a la reclusión”. En: http://www.pazciudadana.cl/docs/pub_20090519144838.pdf. [visitado el 12.11.2009].

HURTADO, Paula, "Diversificando la respuesta frente al delito: Procedimientos y penas alternativas" (2005), pp. 179-198. En: http://www.pazciudadana.cl/docs/pub_20090707161146.pdf [visitado el 12.11.2009].

KURY, Helmut, Sobre la relación entre sanciones y criminalidad, o: ¿Qué efecto preventivo tienen las penas?, Trad.: HERNANDEZ PLASENCIA, José. En: 
Polit. crim. Vol. 4, No 8 (Diciembre 2009), Art. 5, pp. 430-474 (1-45).

[http://www.politicacriminal.cl/Vol_04/n_08/Vol4N8A5.pdf]

Modernas tendencias en la ciencia del derecho penal y en la criminología, Madrid: Universidad Nacional de Educación a Distancia, 2001, p. 304.

KUZIEMKO, Ilyana; LEVITT, Steven, "An empirical analysis of imprisoning drug offenders", Journal of Public Economics, Elsevier, vol. 88 (2004), pp. 2043-2066.

LAVIN, Claudio, "Toma de decisiones y control social del delito". En: http://www.cejamericas.org/doc/documentos/tomadesiciones_delito.pdf [visitado el 12.11.2009].

LEVITT, Steven, "Entendiendo por qué se redujo la Criminalidad en la Década de 1990: Cuatro Factores que lo explican y Seis que No", Trad. MATUS, Jean Pierre; VIDAL, Patricio, Ius et Praxis, 2004, vol. 10, nº 2, pp.97-135.

, "Using electoral Cycles in police hiring to estimate the effects of police on crime", American Economic Review, Vol. 87, n ${ }^{\circ} 3$ (1997), pp. 270-290.

MATUS RAMIREZ, Jean Pierre, "El Ministerio Público y una Política Criminal en una Sociedad Democrática.", Revista de Derecho, Vol. XIX- N 2o, Diciembre (2006), pp. 187-203, p. 194.

" ¿Por qué no bajan las Tasas de Criminalidad en Chile?", Revista de Derecho de la P. U. Católica de Valparaíso, XXVI Valparaíso (2005), Semestre I, pp.67-92, p.84.

POLITOFF, Sergio; MATUS, Jean Pierre; RAMIREZ, María Cecilia, Lecciones de Derecho Penal. Parte General, 2a Ed., Santiago: Editorial Jurídica, 2006, p. 543.

POSADA, Carlos; GONZALEZ, Francisco, "El gasto en defensa, justicia y seguridad". Rev. econ. Inst., vol. 2, no 2, Jan/June (2000), pp. 53-75.

RUIZ, Paulina; CEA, Macarena; RODRÍGUEZ, Carlos; MATUS, Jean Pierre, "Determinantes de la criminalidad: Análisis de Resultados". Polit. crim. no 3 (2007), pp. 1-80.

SERRANO MAILLO, Alfonso, Introducción a la Criminología, Lima-Perú: Edit. Ara, 2004, p. 266.

SOTO NAVARRO, Susana, "La influencia de los medios en la percepción social de la delincuencia." RECPC. 07-09 (2005), pp. 1-46.

STANGELAND, Per, "Encuestas de Victimización" en: DIEZ RIPOLLES, José Luis; CEREZO DOMINGUEZ, Ana Isabel, Los Problemas de la Investigación Empírica en Criminología: La situación española, Valencia: Tirant Lo Blanch, 2001, p. 12.

TAMARIT, Josep M., "Política criminal con bases empíricas en España", Polít. crim. n 3 (2007), pp. 1-16, p.13.

TOWN, Stephen, "Crime Displacement. The perception, problems, evidence and supporting theory", Home Office (2001).

VON HIRSCH, Andrew, Censurar y Castigar, Trad. LARRAURI, Elena, Madrid: Edit. Trotta, 1998, p.1.

WOLPIN, Kenneth, "An Economic Analysis of Crime and Punishment in England and Wales 1894-1967”, Journal of Political Economy, vol. 86 (1978), p. 815.

ZIMRING, Franklin; HAWKINS, Gordon; KAMIN, Sam, "Punishment and Democracy. Three strikes and you're out in California", New York, (2001). 